\title{
Variability in glacier albedo and links to annual mass balance for the gardens of Eden and Allah, Southern Alps, New Zealand
}

\author{
Angus J. Dowson ${ }^{1,2}$, Pascal Sirguey ${ }^{2}$, and Nicolas J. Cullen ${ }^{1}$ \\ ${ }^{1}$ School of Geography, University of Otago, Dunedin, 9016, New Zealand \\ ${ }^{2}$ National School of Surveying, University of Otago, Dunedin, 9016, New Zealand \\ Correspondence: Pascal Sirguey (pascal.sirguey@ otago.ac.nz)
}

Received: 7 January 2020 - Discussion started: 16 January 2020

Revised: 29 July 2020 - Accepted: 22 August 2020 - Published: 17 October 2020

\begin{abstract}
The gardens of Eden and Allah (GoEA) are two of New Zealand's largest ice fields. However, their remote location and protected conservation status have limited access and complicated monitoring and research efforts. To improve our understanding of the spatial and temporal changes in mass balance of these unique ice fields, observations from the Moderate Resolution Imaging Spectroradiometer (MODIS) sensors are used to monitor annual minimum glacier-wide albedo $\left(\bar{\alpha}_{\mathrm{yr}}^{\min }\right)$ over the period $2000-2018$. The $\bar{\alpha}_{\mathrm{yr}}^{\min }$ for 12 individual glaciers ranges between 0.42 and 0.70 and can occur as early as mid-January and as late as the end of April. The evolution of the timing of $\bar{\alpha}_{\mathrm{yr}}^{\min }$ indicates a shift to later in the summer over the 19-year period on 10 of the 12 glaciers. However, there is only a weak relationship between the delay in timing and the magnitude of $\bar{\alpha}_{\mathrm{yr}}^{\min }$, which implies that albedo is not necessarily lower if it is delayed. The largest negative departures in $\bar{\alpha}_{\mathrm{yr}}^{\min }$ (lower-than-average albedo) are consistent with high snowline altitudes (SLAs) relative to the long-term average as determined from the End of Summer Snowline (EOSS) survey, which has been the benchmark for monitoring glaciers in the Southern Alps for over 40 years. While the record of $\bar{\alpha}_{\mathrm{yr}}^{\min }$ for Vertebrae Col 25, an index glacier of the EOSS survey and one of the GoEA glaciers, explains less than half of the variability observed in the corresponding EOSS SLA $\left(R^{2}=0.43, p=0.003\right)$, the relationship is stronger when compared to other GoEA glaciers. Angel Glacier has the strongest relationship with EOSS observations at Vertebrae Col 25, accounting for $69 \%$ of its variance $(p<0.001)$. A key advantage in using the $\bar{\alpha}_{\mathrm{yr}}^{\min }$ approach is that it enables variability in the response of individual glaciers to be explored, revealing that topographic setting plays a key role in addition to the regional climate sig-
\end{abstract}

nal. The observed variability in individual glacier response at the scale of the GoEA contrasts with the high consistency of responses found by the EOSS record across the Southern Alps and challenges the suggestion that New Zealand glaciers behave as a unified climatic unit. MODIS imagery acquired from the Terra and Aqua platforms also provides insights about the spatial and temporal variability in clouds. The frequency of clouds in pixels west of the Main Divide is as high as $90 \%$ during summer months and reaches a minimum of $35 \%$ in some locations in winter. These complex cloud interactions deserve further attention as they are likely a contributing factor in controlling the spatial and temporal variability in glacier response observed in the GoEA.

\section{Introduction}

The retreat of mountain glaciers during periods of the 20th and 21 st centuries has been widespread and unprecedented (Zemp et al., 2015, 2019). One approach to document this change is to monitor glaciological mass balance, which enables the response of glaciers to climate forcing to be assessed (Hock et al., 2019; Zemp et al., 2019). However, global records of mass balance are sparse as traditional in situ glaciological measurements are resource intensive (Cogley et al., 2011), with only 260 glacier-wide results available from an estimated 200000 glaciers worldwide (Pfeffer et al., 2014; Zemp et al., 2015). In addition, the ongoing cost of maintaining the repetitive measurements means that few long-term records exist, with only 30 of the world's glaciers having an uninterrupted series dating back to 1976 (Zemp et al., 2009). Mass balance records are therefore biased to- 
wards the more accessible glaciers in the Northern Hemisphere, while remote and relatively inaccessible glaciers in South America and New Zealand have remained largely out of reach. In this context, there is a need to monitor the state of more mountain glaciers to capture their response to changes in regional and large-scale climate.

Recent developments in the capabilities of satellite and airborne sensors, as well as improved processing techniques, have provided several alternatives to the in situ glaciological approach to derive individual or regional mass balance signals for remote glaciers (Rabatel et al., 2017). For example, mapping the end-of-summer snowline altitude (SLA) provides an estimate of the glacier equilibrium-line altitude (ELA) and accumulation area ratio (AAR). These glacier properties have been used as proxies for annual mass balance and are often less resource intensive to monitor (Chinn et al., 2012; Rabatel et al., 2016; Salinger et al., 2019b). Alternatively, the "albedo method" uses glacier surface albedo, for example retrieved from satellite imagery captured by the Moderate Resolution Imaging Spectroradiometer (MODIS), to estimate glacier mass balance and/or monitor its variations (Rabatel et al., 2017). Surface albedo plays a governing role in the mass balance of glaciers due to its control on absorbed shortwave radiation (Klok and Oerlemans, 2004; Oerlemans et al., 2009; Pope et al., 2016). The annual minimum glacierwide albedo $\left(\bar{\alpha}_{\mathrm{yr}}^{\min }\right)$ retrieved from MODIS imagery has been found to scale to annual glacier mass balance in the French Alps (Dumont et al., 2012; Davaze et al., 2018), the Arctic (Greuell et al., 2007), the Himalayas (Brun et al., 2015; Zhang et al., 2018), and New Zealand's Southern Alps on Brewster and Park Pass glaciers (Sirguey et al., 2016; Rabatel et al., 2017).

The mountain glaciers of the Southern Alps of New Zealand comprise the largest ice mass in the Southern Hemisphere outside of Antarctica and South America and are regarded as globally significant (Chinn et al., 2012; Zemp et al., 2015). The Southern Alps are unique as they are surrounded by vast areas of ocean and are subject to both subtropical and polar air masses that are embedded in a prevailing westerly airflow. This unique setting contributes to the humid, maritime climate that influences the glaciers in the Southern Alps, which is reflected by the exceptionally high precipitation rates exceeding $10 \mathrm{~m} \mathrm{yr}^{-1}$ in many alpine regions (Fitzharris et al., 1999). Meteorological experiments on glaciers in the Southern Alps have shown the main source for melt energy is net radiation, driven primarily by net shortwave radiation (e.g. Gillett and Cullen, 2011; Cullen and Conway, 2015), but fluctuations in mass balance over time are sensitive to changes in air temperature and precipitation. Given the importance of air temperature in controlling both melt and the phase of precipitation, the advance and retreat of glaciers in the wet climate of the Southern Alps are particularly sensitive to changes in air temperature (Oerlemans, 1997; Mackintosh et al., 2017). For example, the advance of some fast-responding glaciers in the Southern Alps be- tween 1983 and 2008, during 3 of the warmest decades on the instrumental record, has been attributed to regional cooling controlled by changes in large-scale atmospheric circulation in the Southern Hemisphere (Mackintosh et al., 2017). The influence of synoptic-scale circulation on air mass variability and changes in cloud properties has also been shown to influence mass balance in the Southern Alps (Conway and Cullen, 2016; Cullen et al., 2019).

The first comprehensive glaciological mass balance study in New Zealand's Southern Alps was completed on Ivory Glacier between 1969 and 1975 (Anderton and Chinn, 1973; 1978). Today, comprehensive glaciological mass balance programmes exist on Brewster Glacier (e.g. Cullen et al., 2017) and Rolleston Glacier (Purdie et al., 2015), extending back to 2004 and 2010, respectively. The size of Brewster Glacier $\left(\mathrm{ca} .2 \mathrm{~km}^{2}\right.$ ) and its comprehensive in situ record enabled the albedo method with MODIS to be assessed and calibrated to estimate mass balance (Sirguey et al., 2016). With only $0.11 \mathrm{~km}^{2}$ in 2012, Rolleston Glacier is however too small to be captured by MODIS imagery. In addition, the End of Summer Snowline (EOSS) survey, which has been the benchmark for monitoring glaciers in the Southern Alps for over 40 years, has used aerial photography to map and retrieve the altitude of the annual snowline (SLA) at the end of the ablation season of 50 "index" glaciers across the Southern Alps since 1977 (Chinn et al., 2012). The SLA is used as a surrogate of the equilibrium-line altitude (ELA) whose annual variations give information about changes in the annual balance of the glaciers (Rabatel et al., 2017). Despite is longevity, the EOSS survey continues to face two main challenges: (1) the temporal resolution is limited to a single observation per year in late summer, the success of which is dependent on transient conditions such as snowfall prior to a flight, and (2) limited resources constrain the total number of index glaciers that can be mapped. Furthermore, the focus on relatively small glaciers in the Southern Alps has meant that only three index glaciers exceed $2 \mathrm{~km}^{2}$. These challenges, combined with the difficulty of establishing a network of glaciological programmes, have resulted in the vast majority of glaciers in New Zealand remaining out of reach of current observation methods.

The EOSS programme indicates that the yearly response of the transient snowline for each of the index glaciers is consistent with the average of the group, with strong to very strong intra-correlations between SLA departures across index glaciers. This consistent response to climate variability inferred from the EOSS record has led to the suggestion that glaciers in the Southern Alps behave as a "unified climatic unit" (Chinn et al., 2012, p. 115). The linear models corresponding to this hypothesis have led to observations from single glaciers, such as Tasman or Brewster Glacier, being used to estimate fluctuations in ice volume for the entire Southern Alps (Salinger et al., 2019a, b). To further explore the validity of this approach, more long-term continuous signals of glacier mass balance are required across a broader to- 
pographical range of glaciers, particularly those larger than $2 \mathrm{~km}^{2}$. Given the available approaches to monitor glaciers and the lack of in situ data, the albedo method is a desirable alternative to objectively resolve mass balance variability and trends on large, unmonitored New Zealand glaciers.

The gardens of Eden and Allah (GoEA), located on the Main Divide of the Southern Alps, northeast of Aoraki/Mt Cook National Park, comprise two of the largest ice fields in New Zealand (Fig. 1). They form an interesting target to test the climatic unit hypothesis, as the ice fields consist of a network of smaller, interconnected glaciers placed in a critical climatic zone straddling the Main Divide. Their position on the Main Divide, combined with their protected conservation status, has greatly constrained the possible methods for data collection and extraction. As a result, these glaciers are yet to be the target of focused research, and their behaviour over the past decades is largely undocumented and poorly understood.

To address this gap in knowledge, the aim of this paper is to characterise the spatial and temporal variability in glacierwide surface albedo on the GoEA and to investigate the linkages between this variability and glacier mass balance. To achieve this aim, this research has the following objectives: (1) to determine the timing and magnitude of glacier-wide surface albedo on 12 different outlet glaciers on the GoEA, (2) to compare the spatial and temporal changes in surface albedo to variability in SLA as determined from the EOSS programme, and (3) to characterise variability in cloud cover using MODIS imagery acquired by the Terra and Aqua platforms. Remote sensing with the albedo method provides an opportunity to examine the significant, yet remote and protected, GoEA ice fields and to further assess the skill of the albedo method to remotely monitor the physical processes governing glacier mass balance in the Southern Alps.

\section{Site description and data}

\subsection{The gardens of Eden and Allah}

\subsubsection{Situation}

The Garden of Eden and Garden of Allah (referred to collectively as the GoEA) are two of New Zealand's largest ice fields (Fig. 1), situated in the Adams Range of the Southern Alps/Kā Tiritiri o te Moana $\left(43^{\circ} 18^{\prime} \mathrm{S}, 170^{\circ} 43^{\prime} \mathrm{E}\right)$. The ice fields are aligned east to west, spanning the Main Divide, $56 \mathrm{~km}$ northeast of Aoraki/Mt Cook. In this context, the GoEA are considered the perennial ice mass (ca. $36 \mathrm{~km}^{2}$ ) of the region, bordered by Outram Peak (2399 m), Mt Barlow $(2100 \mathrm{~m})$, Mt Kensington $(2444 \mathrm{~m})$ and Mt Stoddart $(2223 \mathrm{~m})$. The glaciers extend from a maximum elevation of 2543 m a.s.l. (Newton Peak) to ca. 1100 m a.s.l. at the terminus of Colin Campbell Glacier (southeast of Newton Peak).
The ice fields are centred on two large rock plateaus (ca. $1900 \mathrm{~m}$ a.s.l.), with ice flowing down into broad valley glaciers or terminating in dramatic icefalls over the incised valley walls. These outlets provide meltwater to the catchments of the Rangitata River on the east coast and the Whataroa River and Wanganui River on the west coast. The positioning of the GoEA across the Main Divide places the ice fields in a complex climatic setting. A prevailing westerly airflow combines with strong orographic lifting to generate a large precipitation gradient from west to east across the Main Divide (Henderson and Thompson, 1999). The estimated mean annual rainfall in the area over the period 19722016 ranges from 6000 to $8500 \mathrm{~mm} \mathrm{yr}^{-1}$ (Macara, 2017). The mean annual temperature over the glaciated region for the period 1980-2010 is estimated to range from -1.0 to $2.5^{\circ} \mathrm{C}$ based on an interpolation of mean normal temperature from distant surrounding weather stations and a lapse rate determined from the data of $-5.7^{\circ} \mathrm{C} \mathrm{km}^{-1}$. Given the contribution of snow and ice to New Zealand's water resources, changes in the volume of these ice fields have the potential to impact the hydrology of these rivers under future climate change (Chinn, 2001).

Despite their significance, research on the GoEA is limited by the remote location of the glaciers, and direct access has been further complicated in recent years by their inclusion in the $466 \mathrm{~km}^{2}$ Adams Wilderness Area (est. 11 February 2014). Helicopter landings are now largely prohibited, effectively ruling out a number of in situ monitoring methods. As a result, the only comprehensive data obtained from the area to date are EOSS SLA records for the two Vertebrae glaciers at the western margin of the GoEA (Willsman et al., 2018), which are described in more detail below (Sect. 2.3). The Garden of Eden was also briefly included in an attempt to detect changes in the ELA of New Zealand glaciers from $15 \mathrm{~m}$ resolution ASTER satellite imagery (Mathieu et al., 2009). The absence of data and the notable extent and volume of ice locked in the GoEA make the region a compelling target for research among the more than 2500 glaciers in the Southern Alps.

\subsubsection{Glacier outlines and surface topography}

As part of this research, the boundaries of the ice field outlets were redefined, updating the existing New Zealand Glacier Inventory outlines derived during the 1970s (Chinn, 1991) and refining the 2017 Randolph Glacier Inventory (RGI) version 6.0 outlines (Pfeffer et al., 2014). We used a $10 \mathrm{~m}$ resolution Sentinel-2A image captured on 14 March 2016, in late-summer and cloud-free conditions, as the base of our mapping. This image provided a suitable tradeoff between glacier exposure and illumination to define glacier outlines. Perennial snow and ice in the GoEA were initially segmented using the Normalized Difference Snow Index (NDSI) band ratio, derived from bands 3 (green) and 11 (shortwave infrared) of Sentinel-2, with a threshold of 0.8. Despite strong 

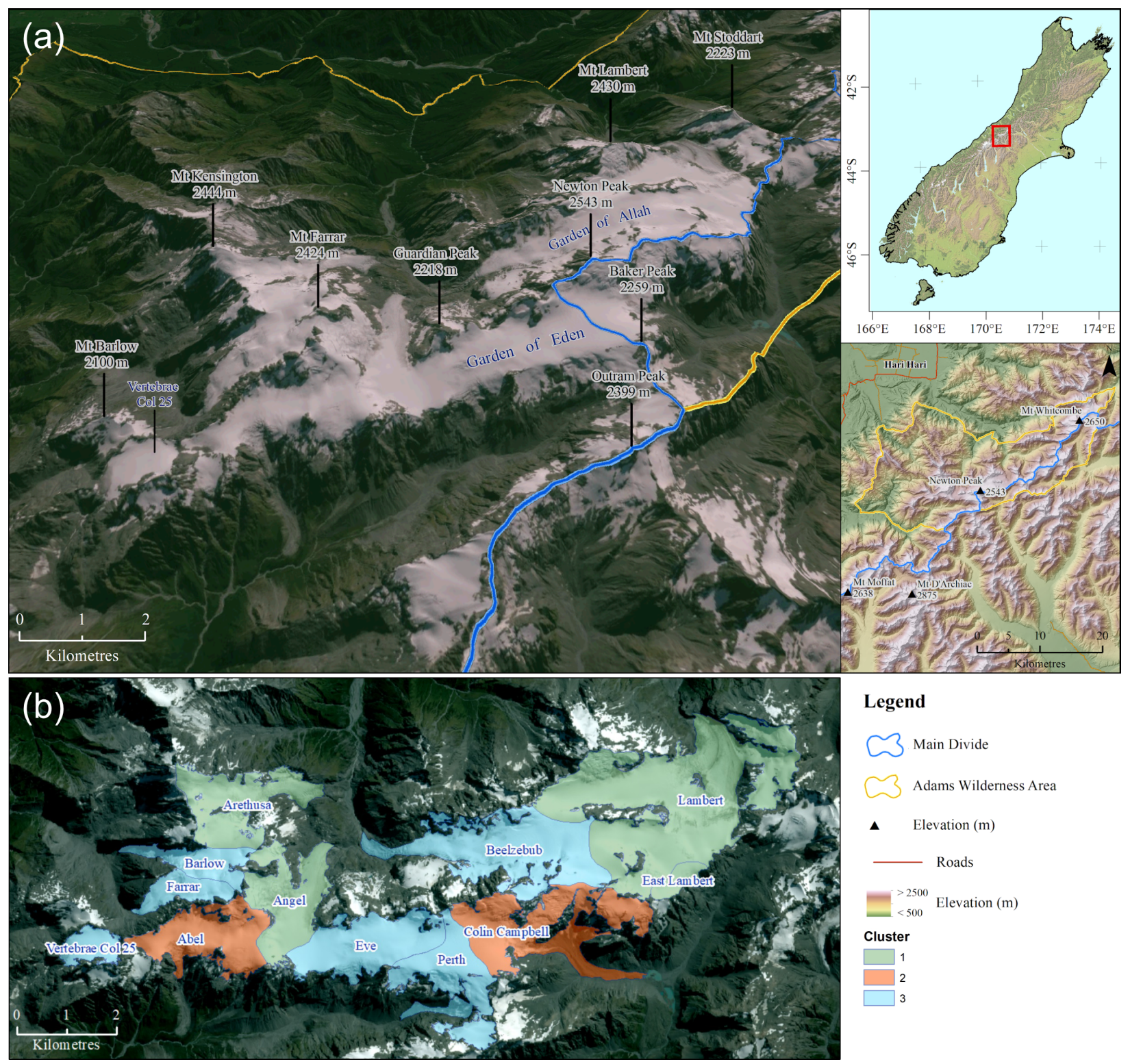

Legend

3 Main Divide

3 Adams Wilderness Area

- Elevation (m)

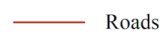

$=<500$ Elevation (m)

Cluster

$\square 1$

$\square$

Figure 1. Location of the Garden of Eden and Garden of Allah within the Adams Wilderness Area, straddling the Main Divide of New Zealand's Southern Alps (a). Sentinel-2A image from 9 March 2017 draped onto a $15 \mathrm{~m}$ resolution NZSoSDEM (Columbus et al., 2011). Outlines of glaciers considered in this study are coloured by clusters (b).

shadowing, a later Sentinel-2 image on 30 April 2016, which appears close to the maximum ablation, provided a visual reference to refine glacier outlines and exclude transient snow patches. Manual edits were made to refine the classification, specifically to correct shaded or debris-covered areas, where detection of snow and ice is impaired. These edits were aided by the interpretation of a $0.5 \mathrm{~m}$ resolution orthorectified pan-sharpened Pléiades-1B satellite image acquired on 10 March 2017 as part of the Pléiades Glacier Observatory (PGO) programme and of a range of oblique aerial and terrestrial photographs captured during fieldwork on 27-28 January 2018.
The outlet glaciers were then delineated from the wider ice fields using topographic divides identified from $20 \mathrm{~m}$ elevation contour vectors surveyed by Land Information New Zealand (LINZ), with refinements based on the interpretation of a preliminary high-resolution surface model derived from the Pléiades stereo acquisition. A total of 17 outlet glaciers were identified in the GoEA. However, this was reduced to 12 , as (1) some small adjacent glaciers $\left(<\right.$ ca. $\left.0.5 \mathrm{~km}^{2}\right)$ were amalgamated into larger units (if the direction of flow was consistent) to create a more suitable target for the MODIS analysis (i.e. O'Neil, Serpent and Cain glaciers), or (2) discrete glaciers $<$ ca. $0.5 \mathrm{~km}^{2}$ were excluded from further anal- 
ysis (i.e. Vertebrae Col 12 and Wee McGregor Glacier). Elevation, slope and aspect data for these 12 outlet glaciers were then derived from the national $15 \mathrm{~m}$ resolution digital elevation model (DEM; NZSoSDEM v1.0; Columbus et al., 2011).

\subsection{MODIS products}

This study relies primarily on a record of glacier surface albedo retrieved from a time series of MODIS images. MODIS is one of the key sensors aboard the Terra (EOSAM-1) and Aqua (EOS-PM-1) satellite platforms, hereafter referred to as MODIS ${ }^{\mathrm{T}}$ and MODIS $^{\mathrm{A}}$, respectively. Terra was launched on 18 December 1999 as the flagship of NASA's Earth Observing System (EOS), allowing MODIS ${ }^{\mathrm{T}}$ to capture near-daily, moderate-resolution images of Earth's surface since 25 February 2000. Aqua was launched in May 2002, creating a second daily opportunity to capture MODIS $^{\mathrm{A}}$ images. The Terra descending node crosses the Equator at approximately 10:30 LT, while Aqua ascending node crosses at 13:30 LT. Historically, MODIS ${ }^{\mathrm{T}}$ imagery has been preferred for the albedo method due to the longer record of imagery, as well as due to failed detectors with MODIS ${ }^{\mathrm{A}}$ Band 6.

Following Sirguey et al. (2009) and Dumont et al. (2012), the albedo retrieval was completed with the MODImLab software as described in Sect. 3.1. As yet, the use of MODIS $^{\mathrm{A}}$ imagery to supplement the MODIS ${ }^{\mathrm{T}}$ record for snow and ice albedo retrieval has not been explored. Wardle (1986) demonstrated the extraordinary cloudy-sky conditions that dominate New Zealand's Southern Alps, greatly reducing the data available to spaceborne remote sensors. Wardle (1986) specifically reported that the western flanks of the study area near Cropp River exhibited the highest frequency of days with some clouds ( $92 \%$ ), as well as days with heavy clouds $(72 \%)$. The frequency of cloudy days tends to decrease towards the east, with some or heavy clouds occurring on $72 \%$ and $38 \%$ of days, respectively. The consideration of MODIS $^{\mathrm{A}}$ data in this study provides an opportunity to compare surface albedo derived from each sensor and to provide information on key climate variables such as cloud frequency and variability over the Southern Alps. If the albedo derived from MODIS ${ }^{\mathrm{A}}$ is suitable, despite the degraded Band 6, it can be used to increase the temporal resolution of the albedo method to two observations per day or to fill gaps in the MODIS $^{\mathrm{T}}$ record.

We use MODIS Level-1B Collection 6 (C6) swath data products that contain calibrated and geolocated top-ofatmosphere (TOA) radiance counts for all 36 spectral bands. The products include bands 1 and 2 supplied at a $250 \mathrm{~m}$ nadir resolution $(\mathrm{MxD} 02 \mathrm{QKM}$ files, $x=O / Y$ for Terra/Aqua, respectively). Bands 3 to 7 are provided at a $500 \mathrm{~m}$ spatial resolution (MxD02HKM files), along with an aggregated $500 \mathrm{~m}$ version of bands 1 and 2. All 36 spectral bands are provided at a $1000 \mathrm{~m}$ resolution (MxD021KM files), including the ag- gregated bands $1-7$ at $1000 \mathrm{~m}$. The accompanying MxD03 file contains the geolocation information and relative geometry parameters, such as solar zenith $\left(\theta_{\mathrm{s}}\right)$, solar azimuth $\left(\varphi_{\mathrm{s}}\right)$, sensor zenith $\left(\theta_{\mathrm{v}}\right)$ and sensor azimuth $\left(\varphi_{\mathrm{v}}\right)$, required to take into account sun-target-sensor geometry in the albedo retrieval (Dumont et al., 2012; Sirguey et al., 2016).

The MODIS ${ }^{\mathrm{T}}$ record over the GoEA consists of 7067 granules between 25 February 2000 and 30 April 2018 captured on 6416 unique days. In addition, MODIS images were selected to compare the surface albedo products from MODIS $^{\mathrm{T}}$ and MODIS ${ }^{\mathrm{A}}$ over the GoEA. Image pairs needed to be captured on the same day, under clear-sky conditions and with a similar near-nadir sensor zenith to mitigate the effect of different panoramic distortions on the pixel footprint between MODIS ${ }^{\mathrm{T}}$ and MODIS ${ }^{\mathrm{A}}$. Four suitable image pairs across separate years near the end of summer were identified as suitable to assess the consistency of albedo retrieval between both sensors, namely 3 March 2009, 9 March 2010, 8 March 2012 and 10 March 2013. At $250 \mathrm{~m}$ resolution, this provided a sufficient sample size of 2196 pairs of albedo from matching pixels that were compared with linear regression and the coefficient of determination $\left(R^{2}\right)$. Finally, a full year of MODIS ${ }^{\mathrm{A}}$ Level-1B images was downloaded between 1 January and 31 December 2012 (448 granules) to assess data loss compared to the MODIS ${ }^{\mathrm{T}}$ record.

\subsection{EOSS survey programme}

The national EOSS programme is run by the National Institute of Water and Atmospheric Research (NIWA). Aerial photos are captured in the first suitable weather window following 1 March. The mapping of SLA for each of the index glaciers implements three methods summarised hereafter (see Willsman et al., 2018). (1) When the snowline is clearly visible, it is sketched from the oblique photograph onto $1: 50000$ topographic contour maps of each glacier, or digitised readily from rectified photos to map the accumulation or ablation zones. The snowline elevation is derived from the ablation area and the hypsometric curve of the glacier. (2) The SLA is often determined by applying an "interpolation method" whereby all EOSS photographs of a glacier are arranged into a sequence of increasing area of snow cover (descending order of SLAs); the SLA value is interpolated from that of the adjacent years. (3) When the snowline is obscured, it is interpolated from an interpretation of the degree of snow cover surrounding the glacier compared to previous years on record.

For each year $i, \mathrm{SLA}_{i}$ records delivered by the EOSS programme for the two Vertebrae glaciers in the GoEA provide an independent dataset to make a comparison with the retrieved albedo signal. Vertebrae Col 25 is a $0.7 \mathrm{~km}^{2}$ mountain glacier facing southwest at the western tip of the Garden of Eden (Fig. 1). Vertebrae Col 12 is a smaller cirque glacier $\left(0.21 \mathrm{~km}^{2}\right)$ located directly adjacently, to the north. The SLA was first recorded for the Vertebrae glaciers in 1978, despite 


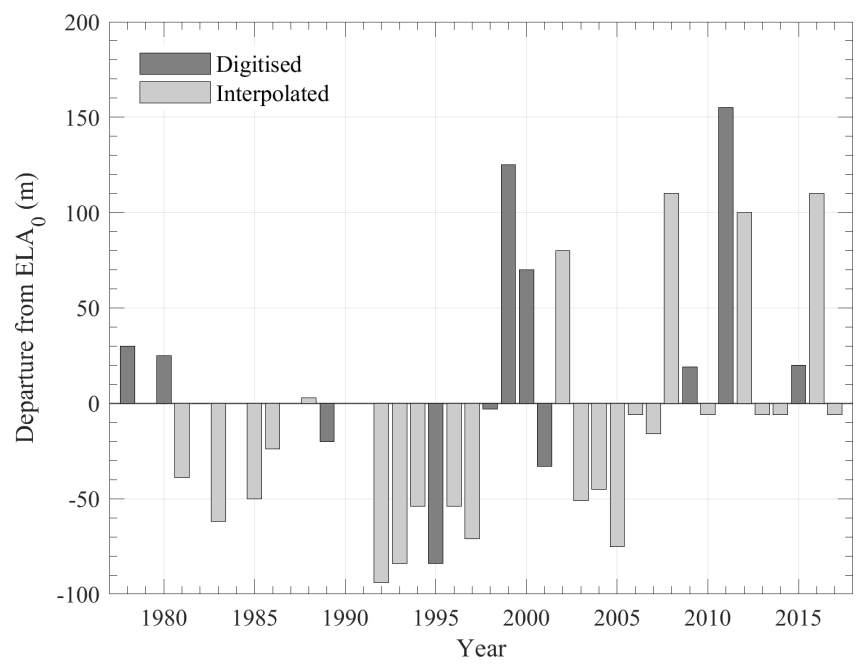

Figure 2. Record of $\mathrm{SLA}_{i}$ departure for Vertebrae Col 25 from $\mathrm{ELA}_{0}$ (1840 ma.s.l.) between 1977 and 2017 (Willsman et al., 2018).

the EOSS survey beginning in 1977, and has been recorded every year since, with the exception of 1979 (no flight), 1984 (no visit), 1987 (no visit), 1990 (no flight) and 1991 (no flight). Of the 35 observations in the 40-year period since 1978, the SLA was digitised 11 times (method 1) and interpolated (method 2 and 3) all the other times (Fig. 2).

As part of the EOSS programme methodology (Chinn et al., 2012; Willsman et al., 2018), the $\mathrm{SLA}_{i}$ for each glacier is compared against the long-term or "steady-state" SLA, termed $\mathrm{ELA}_{0}$, which as determined by the EOSS survey is 1864 and 1840 ma.s.l. for the Vertebrae Col 12 and 25 glaciers, respectively. Vertebrae Col 12 is not considered in this study, as it is not of sufficient size for albedo retrieval with MODIS, however the annual SLA departures from $E_{L A}$ for the two glaciers are strongly correlated $\left(R^{2}=0.95\right)$. The $\mathrm{SLA}_{i}$ departures for Vertebrae Col 25 show 8 years with particularly high seasonal snowlines since 1999 , indicative of a negative glacier mass balance (in particular 1999, 2008, 2011, 2012 and 2016), preceded by a majority of years with snowlines located near or below $\mathrm{ELA}_{0}$, indicative of a positive mass balance.

Both SLA departure records from Vertebrae Col 12 and 25 correlate strongly with the SLA departures averaged over the remaining index glaciers photographed in a particular year $\left(\mathrm{EOSS}_{\mathrm{Alps}} ; R^{2}=0.86\right.$ and 0.92 , respectively; see Willsman et al., 2018). These very strong correlations between individual glacier responses to EOSS $_{\text {Alps }}$ suggest that the Vertebrae Col glaciers, like other index glaciers in the EOSS programme, respond uniformly to climate variability. This high degree of intra-correlation in the EOSS record has led to the theory that glaciers in the Southern Alps behave as a unified climatic unit (Chinn et al., 2012). However, we hypothesise that changes in the climate system are likely to result in greater variability in glacier response in the Southern Alps, which may not be resolved and/or detected by the EOSS programme. The ability to derive and discriminate a mass balance signal from a large number of glaciers in the GoEA using the albedo method, which has a high temporal resolution, provides us with a new opportunity to further characterise the spatial variability in glacier behaviour in the GoEA, as well as to test the consistency in glacier response predicted by the EOSS programme.

\subsection{Sentinel-2 data}

As EOSS SLA $i$ records only exist on two of the smaller glaciers in the GoEA, high-resolution Sentinel-2 data are also used to support the MODIS analysis by observing the evolution of the summer snowline across the ice fields. Launched on 23 June 2015, Sentinel-2 imagery is available for the 2016, 2017 and 2018 summers and provides an independent means to assess the consistency of the albedo products and EOSS survey results. For the three summer periods (1 January-30 April), sequences of cloud-free $10 \mathrm{~m}$ resolution Sentinel-2A and 2B Level-1C images are used to observe the evolution of the GoEA surface until seasonal snow ends the ablation season. There is an expectation that the discolouration of the glacier surface and elevation of the snowline in the Sentinel-2 images depicting maximum ablation will compare and be consistent with relative changes determined by the EOSS survey and minimum glacier-wide albedo (Sirguey et al., 2016). Qualitative results of these observations are presented and discussed for Lambert Glacier, with the elevation of the snowline determined from LINZ $20 \mathrm{~m}$ topographic contours.

\section{Methods}

\subsection{Retrieving snow and ice albedo}

Terra and Aqua MODIS C6 Level-1B products were processed using the MODImLab toolbox (Sirguey et al., 2009). MODImLab has been widely employed to perform a series of image-processing techniques on MODIS time-series data, yielding snow and ice albedo products at a $250 \mathrm{~m}$ resolution (Dumont et al., 2011, 2012; Brun et al., 2015; Sirguey et al., 2016; Rabatel et al., 2017; Davaze et al., 2018). The operations and processes of MODImLab are described by Sirguey et al. (2009) and Dumont et al. (2012) and are only covered here in brief.

First, image fusion combines the higher-resolution MxD02QKM bands 1 and $2(250 \mathrm{~m})$ with the lowerresolution MxD02HKM bands 3 to $7(500 \mathrm{~m})$ to produce seven spectral bands at a $250 \mathrm{~m}$ spatial resolution (Sirguey et al., 2008). As a result, MODIS bands used for mapping snow cover (Band 4 at $555 \mathrm{~nm}$ and Band 6 at $1640 \mathrm{~nm}$ ) have a higher spatial resolution than other common MODIS products (e.g. MxD10 - 500 m). The atmospheric and to- 
pographic correction module (ATOPCOR) then corrects images containing TOA radiance counts into values of ground surface reflectance (Sirguey, 2009). Topographic corrections are calculated from the NZSoSDEM along with the MxD03 product to account for the relative illumination and viewing geometry. The DEM is also used to preprocess the sky view and terrain factor to account for diffuse and terrain-reflected irradiance over rugged terrain and the effects of both self and cast shadow.

The MODImLab algorithm has the ability to resolve the subpixel snow cover fraction in mountainous terrain (Sirguey et al., 2009). Spectral unmixing estimates the relative contributions of specific land cover types to the radiometry of each individual pixel (Masson et al., 2018). Values of spectral albedo (narrowband albedo) for each pixel measured from five MODIS bands are compared against a look-up table (LUT) generated with DISORT (Stamnes et al., 1988). The LUT contains an array of spectral albedo values simulated for snow and ice surfaces with varying snow grain size, impurity type and content, and incident zenith angle (Dumont et al., 2011). The best match of spectral albedo can then be integrated to yield the blue-sky (BS) and white-sky (WS) broadband albedo for a pixel. BS albedo is the value of broadband albedo corresponding to the specific ground irradiance. However, diffuse, or WS, albedo is preferred in this research, as it allows the surface albedo to be studied with reduced sensitivity to seasonal changes in illumination conditions (Dumont et al., 2012). Given the small reflectance of snow and ice targets at $1600 \mathrm{~nm}$ and marginal contribution to broadband albedo, the performance of albedo retrieval from MODIS Aqua data is not expected to be compromised despite the degraded Aqua Band 6.

\subsection{Glacier masks}

Having processed the MODIS granules with MODImLab, we then create $250 \mathrm{~m}$ raster glacier masks using the glacier outlines from Sect. 2.1.2 under which albedo is averaged. Glacier masks are defined from glacier outlines to avoid debris-covered areas or mixed land cover pixels (e.g. containing a combination of snow or ice and rock) so as to preserve the integrity of the snow and ice albedo retrieval. In previous studies, this has been achieved subjectively (e.g. Dumont et al., 2012; Brun et al., 2015; Davaze et al., 2018), but it takes time and introduces variability between users. As a result, we consider an alternative approach to masking that can be more objectively deployed across a large number of glaciers.

From all pixels within the glacier outlines, we use the subpixel snow classification produced by spectral unmixing in MODImLab to exclude those with a snow-covered area of less than $50 \%$ snow, as this threshold is generally used to segment snow from snow-free pixels (Sirguey et al., 2009). This excludes most non-glaciated surfaces from the overall glacier outlines (e.g. debris-covered) and mitigates the effect of mixed pixels in the glacier-wide albedo. We assess the effectiveness of this masking approach (Mask 1) against a conservative glacier mask created manually (Mask 2) by comparing the glacier-wide albedo $\bar{\alpha}(t)$ from each mask and outlet glacier over the full sequence of MODIS ${ }^{\mathrm{T}}$ imagery. The mean surface albedo series retrieved from each mask, $\bar{\alpha}(t)_{\mathrm{M} 1}$ and $\bar{\alpha}(t)_{\mathrm{M} 2}$, are compared using the linear coefficient of determination $\left(R^{2}\right)$, root mean square difference (RMSD) and mean difference (MD).

\subsection{Filtering the MODIS-albedo record}

Despite the near-daily capture of MODIS images over the GoEA, cloud cover in the Southern Alps greatly reduces the quantity of available data. Following Sirguey et al. (2016), only MODIS images with no cloud present in any pixels within the glacier mask are retained in the analysis. Cloudy pixels were determined using MODImLab's cloud detection algorithm, based on the original MODIS MOD35 cloud product described by Ackerman et al. (1998). Using these products, Brun et al. (2015) and Davaze et al. (2018) demonstrated the successful application of a cloud threshold, whereby images are retained so long as a certain proportion of the glacier surface is cloud-free in the image (>20\% and $>30 \%$ clear surface, respectively). While there is merit in this approach for larger glaciers (e.g. Chhota Shigri Glacier, $15.7 \mathrm{~km}^{2}$, and Mera Glacier, $5.1 \mathrm{~km}^{2}$ ), the outlet glaciers of the GoEA identified in this analysis are much smaller (average ca. $2.8 \mathrm{~km}^{2}$ ). On small glaciers, there is a higher probability that large parts of the accumulation or ablation areas will be obscured by clouds, and therefore the surface albedo across the glacier may be misrepresented. Relying on cloudfree conditions over the glacier excluded ca. $66 \%$ of the images, resulting in an average of one clear-sky image every $3 \mathrm{~d}$. The classification of clouds in the complete 19-year long inventory of near-daily MODIS images was then leveraged to characterise the spatial variability in cloud frequency of occurrence around the GoEA.

An increase in the sensor viewing zenith angle $\left(\theta_{\mathrm{v}}\right)$ distorts MODIS pixels due to the panoramic effect. The ground sampling distance of MODIS pixels increases from 2- to 5fold from $\theta_{\mathrm{v}}=45$ to $66^{\circ}$, respectively (Wolfe et al., 1998). Albedo retrieval of mountain glaciers with MODIS is most accurate with $\theta_{\mathrm{v}}<30^{\circ}$ (Sirguey et al., 2016). However, Brun et al. (2015) and Sirguey et al. (2016) accepted $\theta_{\mathrm{v}}<40^{\circ}$ and $<45^{\circ}$, respectively, to increase the number of images available for retrieval. Davaze et al. (2018) confirmed that, while albedo retrieval was most accurate with view angle $\theta_{\mathrm{v}}<30^{\circ}$, it performed well until $\theta_{\mathrm{v}}<45^{\circ}$. In this study, and given the various configurations and sizes of glaciers in the GoEA, we found that this threshold remained suitable for optimising the number of images and quality of the albedo retrieval. 


\subsection{Calculating glacier-wide albedo}

Glacier-wide albedo $\bar{\alpha}(t)$ was then calculated for each MODIS image (at time $t$ ) as an average of all pixel values within each outlet glacier mask. Following Dumont et al. (2011), $\bar{\alpha}(t)$ was calculated using the WS albedo product, under the anisotropic reflectance model. To reduce the noise of the $\bar{\alpha}(t)$ signal and smooth the time series, a three-period rolling average was applied (Sirguey et al., 2016) and was preferred to a fixed-day average, which is heavily influenced by large gaps in the series, driven by persistent cloud cover. The $\bar{\alpha}_{\mathrm{yr}}^{\min }$ was then extracted as the annual minimum glacierwide value of smoothed $\bar{\alpha}(t)$, from the period corresponding to the end of the ablation season (1 January-30 April). Due to complex topography and cast shadows in the GoEA, visual confirmation revealed that when $\bar{\alpha}_{\mathrm{yr}}^{\min }$ is reached outside of this period, it is always due to incorrect albedo retrieval (underestimated) due to inaccurate topographic correction in the shade, as identified by Davaze et al. (2018).

\subsection{Characterising topographic shading}

Shading at the glacier surfaces complicates the topographic correction and has the potential to create errors in the albedo retrieval algorithm. This typically occurs at low sun zenith angles, outside of the late-summer period when $\bar{\alpha}_{\mathrm{yr}}^{\min }$ is reached. Nonetheless, changes in the distribution of shortwave radiation being received at the glacier surface affect processes such as the evolution of surface albedo. Net shortwave radiation is one of the key components of the glacier surface energy balance (SEB). The intensity of solar radiation received at the surface is a function of the time of year (season) and global position (latitude). At a local scale, this relationship is complicated by topography, slope and aspect. Olson and Rupper (2018) show shading from topography (both cast- and self-shading) is a key factor contributing to the SEB. Therefore, in addition to quantifying glacier slope and aspect (Sect. 2.1.2), the ATOPCOR module from MODImLab is used to calculate fractional shading at $250 \mathrm{~m}$ resolution across the glacier surface at the time of image capture. We use the maximum proportion of surface shading (occurring during the winter solstice, when the solar zenith angle is at its maximum) as a simple metric to compare shading between glaciers. A high maximum percentage of topographic shading indicates a topographically confined glacier, while a low maximum percentage indicates an open, unconfined surface that receives radiation year round (e.g. Fig. 3).

\section{Results}

\subsection{Assessing the mask performance}

Between February 2000 and April 2018, the difference between derived glacier-wide albedo $\bar{\alpha}(t)_{\mathrm{M} 1}$ and $\bar{\alpha}(t)_{\mathrm{M} 2}$ is small $(\mathrm{RMSD}=0.037$; Table 1 ), with Mask 1 (objective
Table 1. Comparison of $\bar{\alpha}(t)$ between Mask 1 and Mask 2 from Terra MODIS images between 25 February 2000 and 30 April 2018. Statistics are calculated as average values from the 12 outlet glaciers.

\begin{tabular}{lrrr}
\hline & $R^{2}$ & RMSD & MD \\
\hline Annual & 0.902 & 0.037 & -0.012 \\
Winter (April-September) & 0.899 & 0.040 & -0.010 \\
Summer (October-March) & 0.910 & 0.030 & -0.013 \\
\hline
\end{tabular}

masking approach) typically yielding smaller albedo compared to Mask $2(\mathrm{MD}=-0.012)$. The linear agreement between the masks is highest during the critical summer period (1 October-31 March), when $\bar{\alpha}_{\mathrm{yr}}^{\min }$ is expected to be reached. The increased difference during winter months is likely a result of debris-covered pixels (not considered by Mask 2) that become snow-covered beyond $50 \%$, thus included in Mask 1 and raising $\bar{\alpha}(t)$. The relatively small difference between the two methods, particularly during summer, is confirmation of the suitability of the objective glacier masking approach and is therefore used to produce the following results over the GoEA.

\subsection{Glacier characteristics}

Despite the two ice fields being an interconnected ice mass, the glaciers of the GoEA exhibit large differences in their hypsometry (Table 2). The majority of the ice resides slightly above $1900 \mathrm{~m}$ a.s.l., close to the average elevation of the plateaus. As with many other glaciers in the Southern Alps, the average surface gradient is steep, with a number of glaciers approaching $20^{\circ}$. In addition, glacier size is relatively small, ranging between 0.44 and $4.44 \mathrm{~km}^{2}$. Lambert Glacier is an exception $\left(9.44 \mathrm{~km}^{2}\right)$, comprising over one-quarter of the total surface area $\left(33.89 \mathrm{~km}^{2}\right)$. The glaciers also occupy a range of aspects with variable topographic shading. As expected, glaciers with mean northfacing aspects display lower values of topographic shading than south-facing glaciers (e.g. Angel Glacier, east-northeast, $5.4 \%$; Colin Campbell, south, $82 \%$ ).

It is anticipated that the large topographic differences between outlet glaciers may drive a large variability in the temporal evolution of glacier surface albedo. To further characterise the contrasting topography of these glaciers, we perform a $K$-means cluster analysis based on mean aspect, mean slope and maximum topographic shading derived from the mapped outlines of each glacier. The glacier characteristics (Table 2) when viewed in scatter plots revealed that the 12 outlet glaciers are grouped into three identifiable clusters, with the contrasting hypsometry indicated in Fig. 4. Cluster membership for each glacier is provided in Table 2. Glaciers in Cluster 2 are characterised by southerly aspects, steep slopes and incised topography (indicated by topographic shading exceeding $80 \%$ ). These glaciers contrast to 
(a)
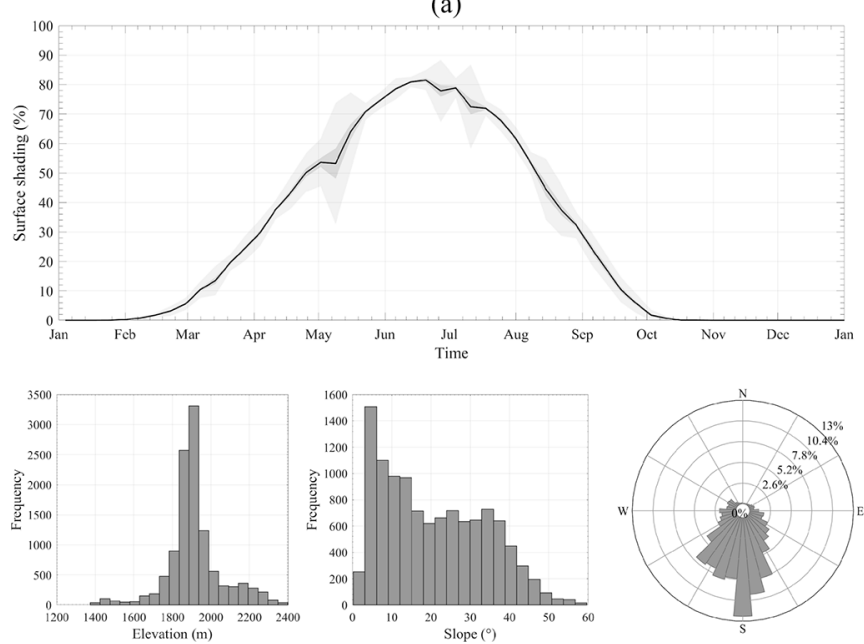

(b)
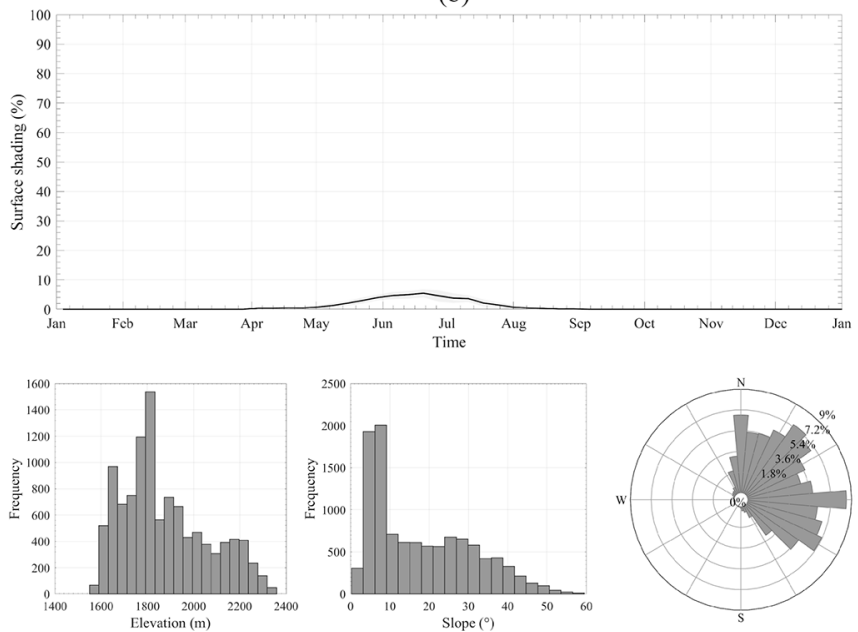

Figure 3. Surface shading and hypsometry of (a) Abel Glacier and (b) Angel Glacier in the GoEA. Shading is displayed over 1 year, calculated as a weekly average between 2000 and 2018, used to indicate the nature of the surrounding topography. Topographic measures of (a) elevation, (b) slope and (c) aspect are calculated at $15 \mathrm{~m}$ resolution from the NZSoSDEM.

Table 2. Physical characteristics of the 12 outlet glaciers in the GoEA identified for MODIS-albedo retrieval, calculated from the $15 \mathrm{~m}$ resolution NZSoSDEM. Cluster membership is defined by $K$-means cluster analysis of aspect, slope and topographic shading. An estimate of the number of $250 \mathrm{~m}$ raster pixels in each individual glacier mask can be found by dividing the total area by $0.0625 \mathrm{~km}^{2}$.

\begin{tabular}{|c|c|c|c|c|c|c|}
\hline $\begin{array}{l}\text { Glacier } \\
\text { Name }\end{array}$ & $\begin{array}{r}\text { Area } \\
\left(\mathrm{km}^{2}\right)\end{array}$ & Aspect & $\begin{array}{r}\text { Elevation } \\
(\mathrm{m})\end{array}$ & $\begin{array}{r}\text { Slope } \\
\left({ }^{\circ}\right)\end{array}$ & $\begin{array}{l}\text { Topographic } \\
\text { Shading (\%) }\end{array}$ & Cluster \\
\hline Abel & 2.57 & $\mathrm{~S}$ & 1918.7 & 20.7 & 81.5 & 2 \\
\hline Arethusa & 2.57 & $\mathrm{E}$ & 1950.3 & 21.9 & 15.6 & 1 \\
\hline Barlow & 1.09 & $\mathrm{~W}$ & 2027.1 & 18.7 & 51.4 & 3 \\
\hline Beelzebub & 4.44 & $\mathrm{~W}$ & 2045.5 & 17.5 & 43.8 & 3 \\
\hline Colin Campbell & 3.95 & $\mathrm{~S}$ & 2008.7 & 24.8 & 82.0 & 2 \\
\hline Eve & 2.73 & SW & 1918.1 & 15.9 & 68.4 & 3 \\
\hline Farrar & 0.86 & W & 1986.2 & 20.0 & 64.5 & 3 \\
\hline Lambert & 9.44 & $\mathrm{NE}$ & 1921.4 & 16.7 & 25.5 & 1 \\
\hline Perth & 2.56 & SW & 1985.2 & 18.9 & 64.9 & 3 \\
\hline Unnamed East (East Lambert) & 0.44 & ENE & 1971.0 & 14.5 & 15.4 & 1 \\
\hline Unnamed West (Angel Gl.) & 2.54 & ENE & 1874.3 & 18.0 & 5.4 & 1 \\
\hline Vertebrae Col 25 & 0.70 & SW & 1882.7 & 11.7 & 50.0 & 3 \\
\hline
\end{tabular}

the north- and east-facing, unconfined glaciers in Cluster 1. Cluster 3 shares similar topographical attributes to Cluster 1, although the aspect is primarily west-facing. Importantly, the glaciers in clusters 1 and 3 account for $81 \%$ of the total surface area of the GoEA, while the two south-facing glaciers in Cluster 2 occupy the remaining $19 \%$.

\subsection{Annual evolution of MODIS-derived glacier-wide albedo}

All 12 glaciers in the GoEA exhibit a marked seasonal evolution of MODIS-derived glacier-wide albedo $\bar{\alpha}(t)$ when averaged within clusters (Fig. 5a), characterised by a decrease in $\bar{\alpha}(t)$ at the end of the austral winter as controlled by the onset of melt. The lowering of $\bar{\alpha}(t)$ is primarily due to the melting of snow from the previous winter, exposing the underlying glacier ice and firn. To compound this process, snow and ice that remain through the summer undergoes metamorphism. This process drives an increase in grain size, liquid water content and impurity concentration, which all act to decrease surface albedo. As a result, glacier-wide albedo continues to fall until fresh snow begins to accumulate in late summer and early autumn. The duration of exposure of discoloured glacier ice and firn across the glacier during summer is a critical part of the physical processes controlling surface ablation. Although each of the three clusters follows a typical pattern of seasonal evolution, the timing and magnitude of key events, such as the $\bar{\alpha}_{\mathrm{yr}}^{\min }$ and the rate of change in $\bar{\alpha}(t)$, varies between glaciers. 

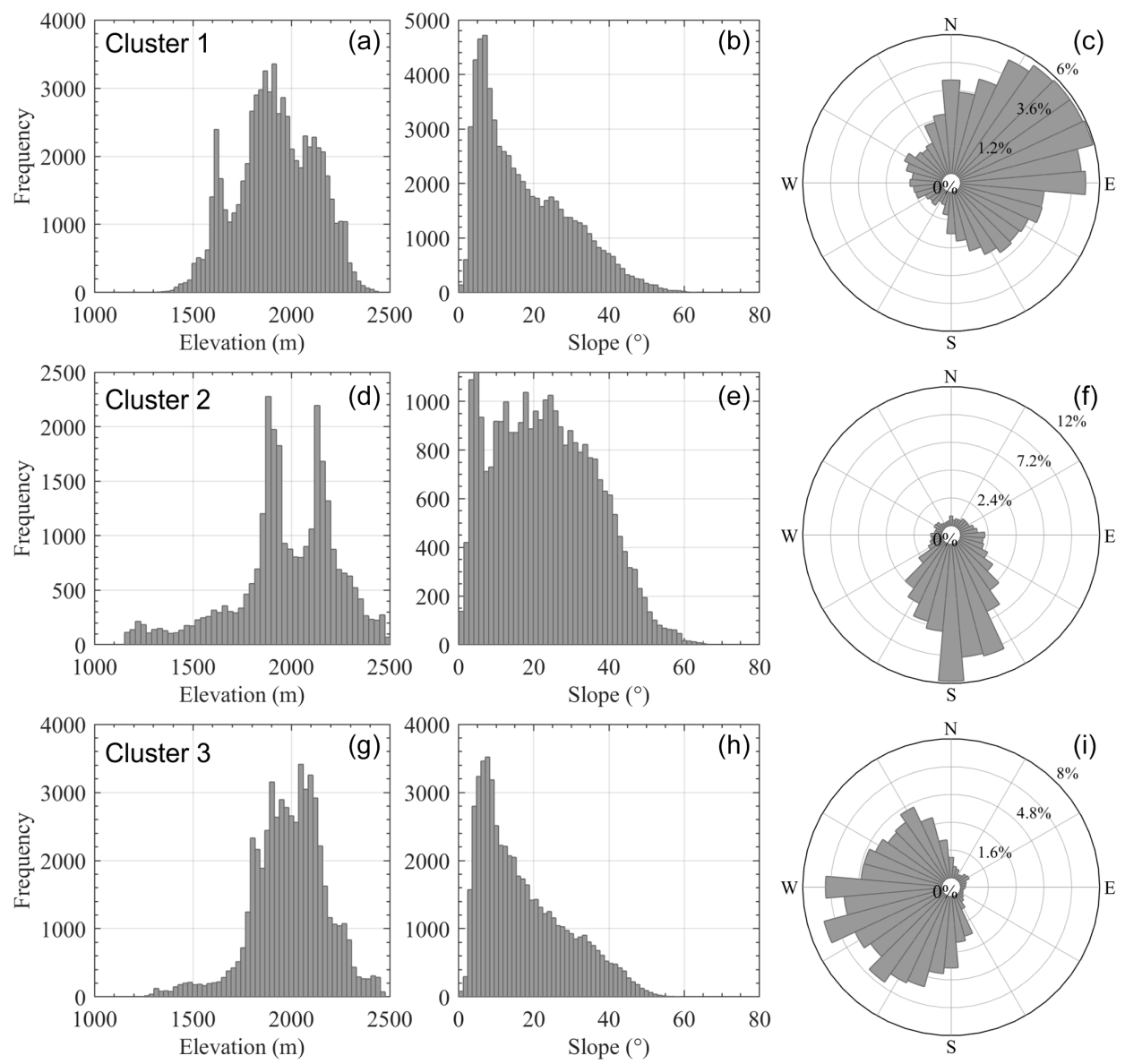

Figure 4. Topographic measures of $(\mathbf{a}, \mathbf{d}, \mathbf{g})$ elevation, $(\mathbf{b}, \mathbf{e}, \mathbf{h})$ slope and $(\mathbf{c}, \mathbf{f}, \mathbf{i})$ aspect are calculated at $15 \mathrm{~m}$ resolution from the NZSoSDEM for Cluster $1(\mathbf{a}-\mathbf{c})$, Cluster $2(\mathbf{d}-\mathbf{f})$ and Cluster $3(\mathbf{g}-\mathbf{i})$ in the GoEA.

On some glaciers, the seasonality of the albedo signal is complicated by a substantial decrease in $\bar{\alpha}(t)$ centred around the winter solstice (21-22 June). This trend is not unique to the GoEA and has been identified as an artefact of widespread surface shading when the sun is at its lowest, which compromises the radiometric correction by MODImLab, resulting in incorrect surface albedo (Rabatel et al., 2017; Davaze et al., 2018). This issue affects both glaciers in Cluster 2 (observable in Fig. 5a) and some in Cluster 3 (namely, Eve Icefall and Perth Glacier). These glaciers all exhibit a south or southwest aspect and topographic shading greater than $60 \%$ (Table 2). As this pitfall develops in winter, it has little or no impact on the summer albedo signal and the identification of $\bar{\alpha}_{\mathrm{yr}}^{\min }$. We therefore disregard much of the winter signal from these glaciers and focus on the summer ablation period.

During the ablation period, all three classes share consistent patterns over the 19-year albedo record that deviate from a monotonic decrease. Short-lived increases in $\bar{\alpha}(t)$ occur in mid-October and December, suggesting synoptic-scale atmospheric processes result in late snowfall events, which temporarily change the albedo signal over the glaciers. A similar pattern of late-spring or early-summer snowfall events was also observed on Brewster Glacier between November and December (Sirguey et al., 2016), which has a strong and coherent weather-system-scale signature (Cullen et al., 2019). The occurrence of these snow events likely plays a considerable role in the evolution of albedo through the summer period and, in turn, of glacier mass balance. Large events have the potential to deposit enough fresh snow at the surface to provide prolonged protection of the otherwise exposed glacier ice during the height of summer.

\subsection{Annual minimum glacier-wide albedo $\left(\bar{\alpha}_{\mathrm{yr}}^{\min }\right)$}

Figure 6 demonstrates the variability in the $\bar{\alpha}_{\mathrm{yr}}^{\min }$ observed over the 19-year period between individual glaciers. The average magnitude of $\bar{\alpha}_{\mathrm{yr}}^{\min }$ varies between 0.50 (Arethusa Glacier) and 0.62 (Eve Icefall), but ranges between 0.42 and $0.70 . \bar{\alpha}_{\mathrm{yr}}^{\min }$ is typically reached between early February (Abel Glacier, 37 Julian days - JD) and mid-March (Barlow Glacier, $75 \mathrm{JD}$ ) but can occur as early as mid-January and as late as the end of April. In addition to a large range in timing between glaciers, the variability in the arrival of $\bar{\alpha}_{\mathrm{yr}}^{\min }$ 

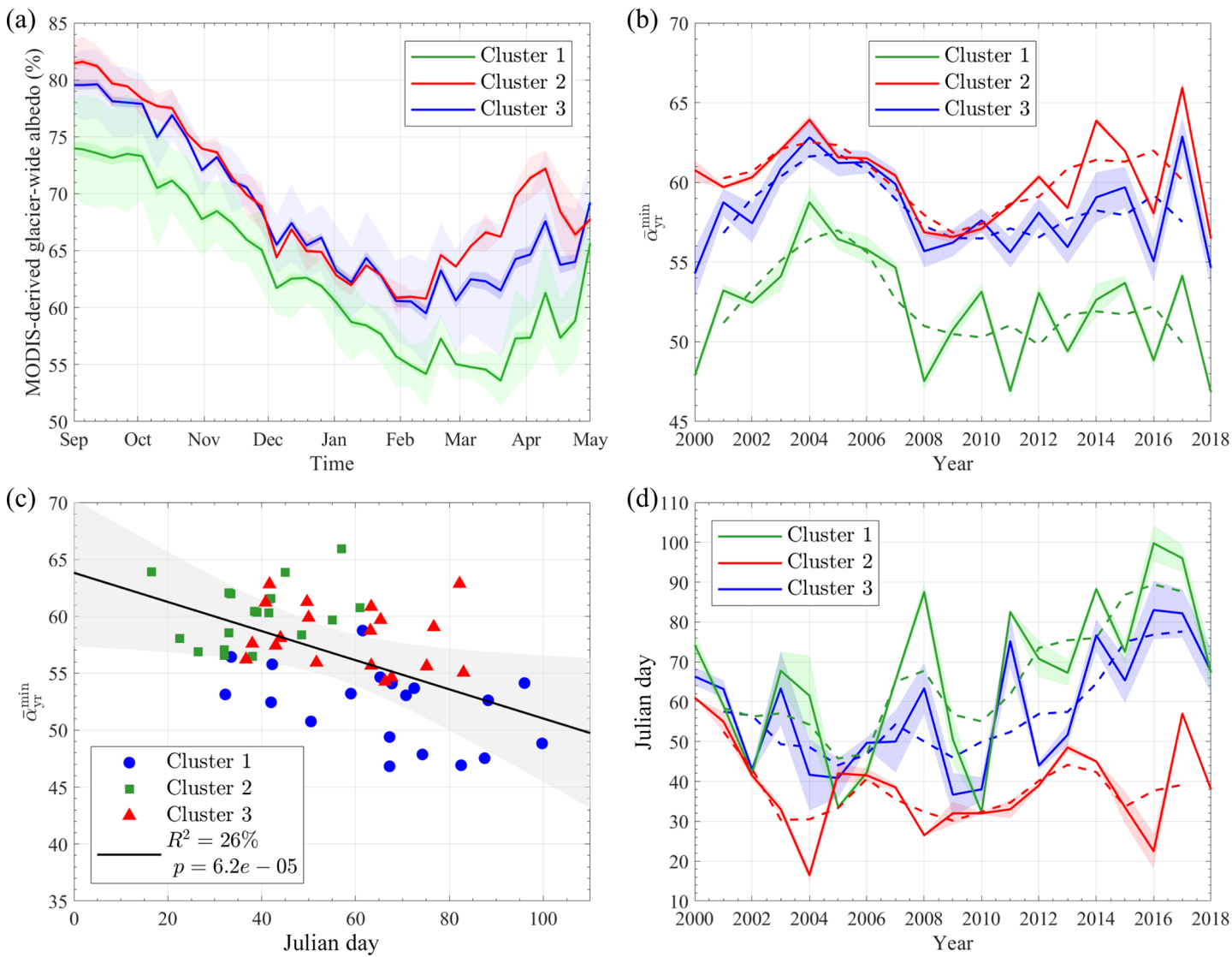

Figure 5. (a) MODIS-derived glacier-wide albedo $\bar{\alpha}(t)$ between September and May of the outlet glacier averaged within clusters. Values are calculated between February 2000 and April 2018 as a mean weekly average. The dark and light shaded envelopes show the standard error and standard deviation of the mean, respectively. (b) Temporal changes in $\bar{\alpha}_{\mathrm{yr}}^{\min }$ averaged within clusters. (c) Correlation between $\bar{\alpha} \mathrm{yr}$ and its timing in Julian days; the grey envelope shows the $95 \%$ confidence interval for the linear regression model. (d) Temporal changes in the timing of $\bar{\alpha}_{\mathrm{yr}}^{\min }$ in Julian days averaged within clusters. Dotted lines show 3-year moving average.

on certain glaciers is also large (e.g. $\sigma=29.5 \mathrm{~d}$ for Barlow Glacier).

The Spearman's rank coefficient is used to determine the topographic controls on the median value and timing of $\bar{\alpha}_{\mathrm{yr}}^{\min }$ across the outlet glaciers (Table 3 ). To avoid the circular nature of aspect data (i.e. where 0 and $360^{\circ}$ are equal), values of mean aspect (in degrees) are converted into Cartesian coordinates and correlated independently. A strong and significant association is found between the magnitude of $\bar{\alpha}_{\mathrm{yr}}^{\min }$ and the proportion of topographic shading $(r=0.741$, $p=0.008$ ). Similarly, strong and significant associations are also found with the timing of $\bar{\alpha}_{\mathrm{yr}}^{\min }$ (north-south component of glacier aspect, $r=0.805, p<0.002$; proportion of topographic shading, $r=-0.782, p=0.003$ ). These correlations, as well as Fig. 6, suggest that glaciers with northerly aspects and low topographic shading (Cluster 1) exhibit a lower and delayed $\bar{\alpha}_{\mathrm{yr}}^{\min }$. Conversely, glaciers with southerly aspects and heavy topographic shading (Cluster 2) typically have a higher $\bar{\alpha}_{\mathrm{yr}}^{\min }$, which occurs earlier in the year.
Interestingly, Fig. 5d shows that despite a large interannual variability, the timing of $\bar{\alpha}_{\mathrm{yr}}^{\min }$ appears to have evolved over the period 2010-2018 towards late summer for clusters 1 and 3 , while this timing remained relatively unchanged for the two glaciers in Cluster 2. However, Fig. 5b reveals no significant temporal trend for $\bar{\alpha}_{\mathrm{yr}}^{\min }$ within each cluster (the Pearson correlation coefficient between $\bar{\alpha}_{\mathrm{yr}}^{\min }$ and the year yielded $p=0.20,0.70$ and 0.52 for clusters 1,2 and 3 , respectively). A delayed $\bar{\alpha}_{\mathrm{yr}}^{\min }$ could indicate a longer ablation duration and consequently correspond to a lower $\bar{\alpha}_{\mathrm{yr}}^{\min }$. However, we only find a weak relationship between $\bar{\alpha}_{\mathrm{yr}}^{\min }$ and its timing when aggregating the three clusters $\left(R^{2}=0.26, p<0.001\right.$; see Fig. 5c). This correlation proves to be weaker when considering all glaciers individually, with the Julian day of the minimum albedo only explaining $11 \%(p<0.001)$ of the variability in $\bar{\alpha}_{\mathrm{yr}}^{\min }$. Furthermore, this relationship loses significance within clusters (Cluster $1, R^{2}=0.20, p=0.058$; Cluster $2, R^{2}=0.08, p=0.248$; Cluster $3, R^{2}=0.03, p=$ 0.472 ). 

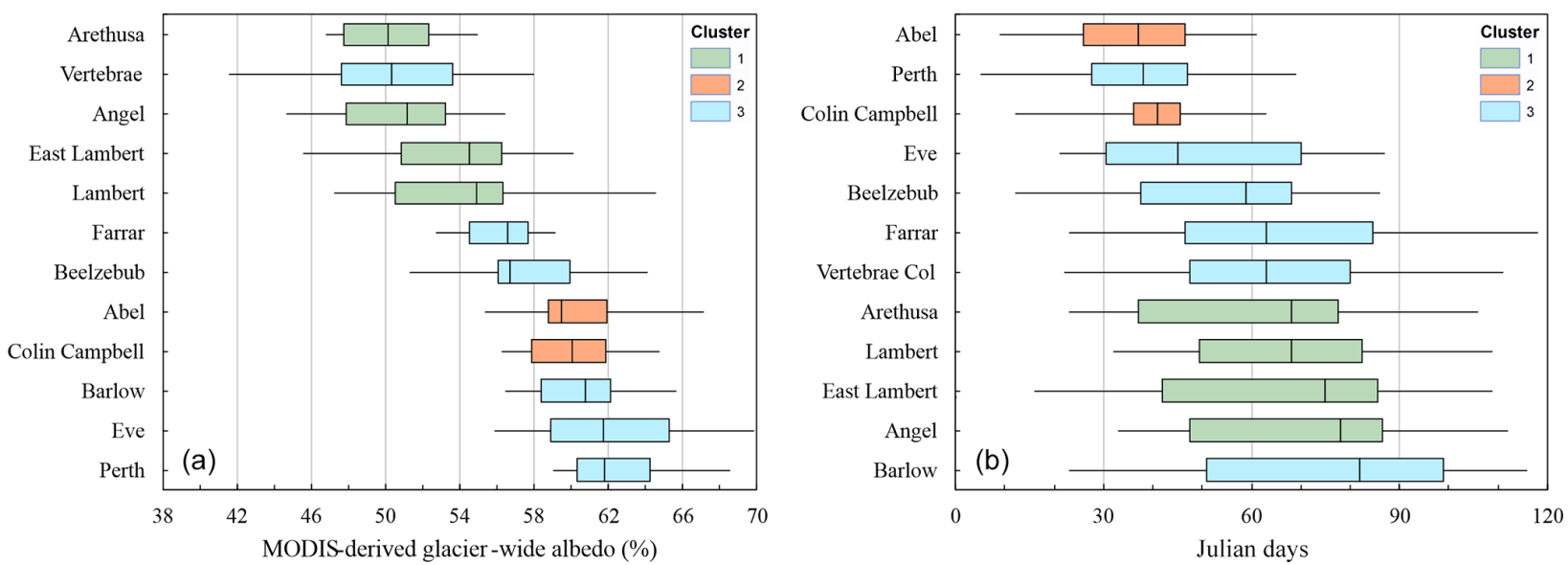

Figure 6. The (a) magnitude and (b) timing of the $\bar{\alpha} \min$ over the 12 outlet glaciers of the GoEA between 2000 and 2018 . The box plots represent the 19-year median, minimum, maximum and interquartile range of each of the glaciers.

Table 3. Correlation between the median timing and magnitude of the $\bar{\alpha} \min _{\mathrm{yr}}^{\mathrm{in}}$ and glacier hypsometry using Spearman's rank coefficient ( $r$ ) for the 12 outlet glaciers of the GoEA. Two-tailed correlation is significant at the 0.05 level $\left(^{*}\right)$ and the 0.01 level $\left(^{* *}\right)$.

\begin{tabular}{|c|c|c|c|c|c|c|}
\hline & \multirow{2}{*}{$\begin{array}{r}\text { Elevation } \\
\text { (m) }\end{array}$} & \multirow{2}{*}{$\begin{array}{r}\text { Slope } \\
\left({ }^{\circ}\right)\end{array}$} & \multicolumn{2}{|c|}{ Aspect } & \multirow{2}{*}{$\begin{array}{r}\text { Area } \\
\left(\mathrm{km}^{2}\right)\end{array}$} & \multirow{2}{*}{$\begin{array}{r}\text { Topographic shading } \\
(\%)\end{array}$} \\
\hline & & & $\cos (\theta)$ & $\sin (\theta)$ & & \\
\hline $\bar{\alpha}_{\mathrm{yr}}^{\min }(\%)$ & 0.406 & 0.196 & -0.489 & -0.555 & 0.251 & $0.741^{* *}$ \\
\hline $\bar{\alpha}_{\mathrm{yr}}^{\min }(t)$ & 0.049 & -0.319 & $0.805^{* *}$ & 0.225 & -0.361 & $-0.782^{* *}$ \\
\hline
\end{tabular}

\subsection{Gardens of Eden and Allah (2000-2018)}

We use the same methodology as the EOSS survey to characterise and compare the variability in $\bar{\alpha}_{\mathrm{yr}}^{\min }$ across the 12 outlet glaciers. $\bar{\alpha}_{\mathrm{yr}}^{\min }$ across the 12 outlet glaciers is averaged to establish $\bar{\alpha}_{0}^{\min }(56.5 \%)$, from which yearly departures are calculated. The combined 19 -year record of $\bar{\alpha}_{\mathrm{yr}}^{\min }$ variability averaged across the 12 outlet glaciers of the GoEA is shown in Fig. 7. The use of $\bar{\alpha}_{0}^{\min }$ follows the theory outlined by the EOSS survey, where the long-term average elevation of the SLA is assumed to approximate a glacier in its equilibrium state. The main limitation of $\bar{\alpha}_{0}^{\min }$ is that the record only consists of 19 years of data, as opposed to almost 40 years for the EOSS survey. In addition, there is no compelling proof that glaciers in the Southern Alps have been in equilibrium during either period. Therefore, it is possible that the value of $\bar{\alpha}_{0}^{\min }$ proposed here actually represents the GoEA in a state that is not in equilibrium. In this instance, $\bar{\alpha}_{0}^{\min }$ is limited to describing relative change over the observation period, as opposed to providing a measure for quantitative mass balance in absolute terms.

Negative departures from $\bar{\alpha}_{0}^{\min }$ correspond to years where the glacier-wide minimum albedo is lower than average, and in turn a more negative mass balance than average is expected. The opposite is expected for positive departures. Therefore, based on the relationship between $\bar{\alpha}_{\mathrm{yr}}^{\min }$ and an- nual mass balance, it can be inferred that these shifts broadly correspond to relative shifts in glacier mass balance. In general, the glaciers of the GoEA appear to have undergone four changes to $\bar{\alpha}_{\mathrm{yr}}^{\min }$ since 2000 . For the first 3 years of the record (2000-2002), $\bar{\alpha}_{\mathrm{yr}}^{\min }$ across the GoEA was close to, or below, average, followed by a positive shift for 2003-2007, with a maximum positive departure in $2004(5.11 \%)$. Between 2008 and 2013, departures were largely negative, notably in 2008, 2011 and 2013. However, since 2014 the fluctuation in $\bar{\alpha}_{\mathrm{yr}}^{\min }$ has increased substantially, highlighted by the very positive year in 2017 and very negative years of 2016 and 2018. The departure in 2018 is the most negative departure across the entire MODIS record ( $4.21 \%$ below $\left.\bar{\alpha}_{0}^{\min }\right)$. This value is also consistent with observations at Brewster Glacier and confirms the widespread effect of the 2018 summer heatwave on New Zealand glaciers (Salinger et al., 2019a).

The behaviour of the glacier-wide surface albedo anomaly on the GoEA over this 19-year period couples reasonably well with EOSS $_{\text {Alps }}$, with about half of the variability explained $\left(R^{2}=0.55, p<0.001\right)$. Notably, the largest negative departures in $\bar{\alpha}_{\mathrm{yr}}^{\min }$ are in general consistent with high snowlines observed across the index glaciers of the Southern Alps in 2000, 2008, 2011, 2016 and 2018. Despite the relatively limited length of the series, the agreement between the two methods in years where the snowline departure is positive $\left(R^{2}=0.68, n=9, p=0.006\right)$ is much stronger 


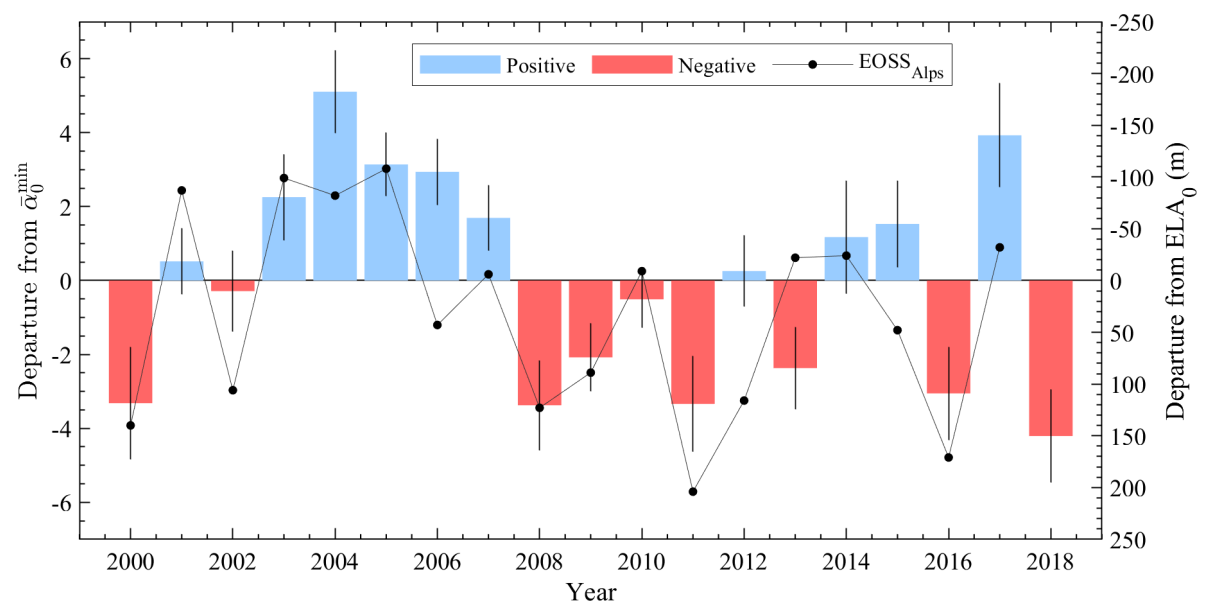

Figure 7. Annual departure and standard error of the mean $\bar{\alpha}_{\mathrm{yr}}^{\min }$ across the 12 outlet glaciers from the long-term average $\bar{\alpha}_{\mathrm{yr}}^{\min }\left(\bar{\alpha}_{0}^{\min } ; 56.5 \%\right)$ between 2000 and 2018. The average annual departure of the EOSS index glaciers from their respective ELA EOSS $\left._{\mathrm{Alps}}\right)$ is also included. Linear agreement between the records is $R^{2}=0.55$.

than in years with a negative departure $\left(R^{2}=0.22, n=9\right.$, $p=0.201$ ). Salinger et al. (2019a) also highlight the overwhelmingly positive departures of the transient snowline during the 2018 summer, with EOSS $_{\text {Alps }}$ estimated to be $386 \mathrm{~m}$ above the long-term average from linear regression with the EOSS of Tasman Glacier alone. Since this estimate is derived with a very different methodology than the traditional EOSS survey, it is not included in the current analysis. Nonetheless, such a large positive departure is supported by widespread reports of exceptional ablation of glaciers in the Southern Alps. The effect of this extreme summer on the GoEA glaciers is now also supported by results in this study using the MODISdriven albedo method.

\subsection{Assessment of $\bar{\alpha}_{\mathrm{yr}}^{\min }$ on Lambert Glacier (2016-2018)}

The full 19-year time series of $\bar{\alpha}(t)$ retrieved from Lambert Glacier exemplifies the annual variability in $\bar{\alpha}_{\mathrm{yr}}^{\min }$ (Fig. 8). The raw MODIS-derived values of $\bar{\alpha}(t)$ are indicated in red, along with the three-period rolling average used to illustrate the seasonality of the albedo signal. In lieu of the glaciological mass balance data needed to relate the $\bar{\alpha}$ min to quantitative mass balance, we use Sentinel-2 data to independently support the MODIS record. The images in Fig. 9 show the end of the ablation season and maximum altitude reached by the summer snowline observed on Lambert Glacier in Sentinel2 images during the 2016, 2017 and 2018 summer periods. Figure 9a shows the snowline captured on 30 April 2016, $12 \mathrm{~d}$ later than the $\bar{\alpha}_{\mathrm{yr}}^{\min }$ estimated from the MODIS record (18 April). The snowline can be distinguished by the separation between the bright white snow and discoloured ice and firn, visible above ca. $1900 \mathrm{~m}$ and up to $2000 \mathrm{~m}$ at some locations. The snowline in the 29 March 2017 image is located at ca. $1820 \mathrm{~m}$, slightly above the large icefall that separates the upper and lower glacier. A much higher proportion of snow covering the glacier surface corresponds to a $6 \%$ increase in the $\bar{\alpha}_{\mathrm{yr}}^{\min }$ during the 2017 summer, which is found to be $10 \mathrm{~d}$ later using the albedo method ( 8 April). This is consistent with the lower ablation reported by the EOSS programme in 2017 (Willsman et al., 2018). Despite a relatively large snowfall event brought by Cyclone Gita in mid-February 2018, the image from 29 March 2018 reveals high ablation and a similar snowline to 2016, although the proportion of exposed ice and firn appears to be slightly larger. These events are captured in the albedo record, with a short-lived rise in $\bar{\alpha}(t)$ corresponding to Gita during February. $\bar{\alpha}_{\mathrm{yr}}^{\min }$ is reached $19 \mathrm{~d}$ earlier (10 March) than the chosen Sentinel-2 image, with its magnitude lower than in 2016. The Sentinel-2 observations are consistent with the relative changes in $\bar{\alpha}_{\mathrm{yr}}^{\min }$ captured by the albedo method, as well as with the effects of heatwaves on New Zealand glaciers in 2016 and 2018 (Salinger et al., 2019a, b; Willsman et al., 2017).

The Sentinel-2 images shown in Fig. 9 also illustrate the complexity of defining the summer snowline elevation on topographically complex glaciers such as Lambert. Despite the limited number of cloud-free images, the sequence of Sentinel-2 images obtained during the summer and through to the arrival of seasonal snow proved to be key in interpreting the evolution of the snowline. They were found to be available within a period of less than 3 weeks from $\bar{\alpha}_{\mathrm{yr}}^{\min }$ determined using the albedo method, while the 2016 and 2017 EOSS surveys captured Vertebrae Col glacier on 11 and 9 March, or 40 and $38 \mathrm{~d}$ earlier than $\bar{\alpha}_{\mathrm{yr}}^{\min }$, respectively (see the albedo record for Vertebrae Col glacier in Fig. 10; note that reports from the EOSS 2018 campaign have not been released to date). 


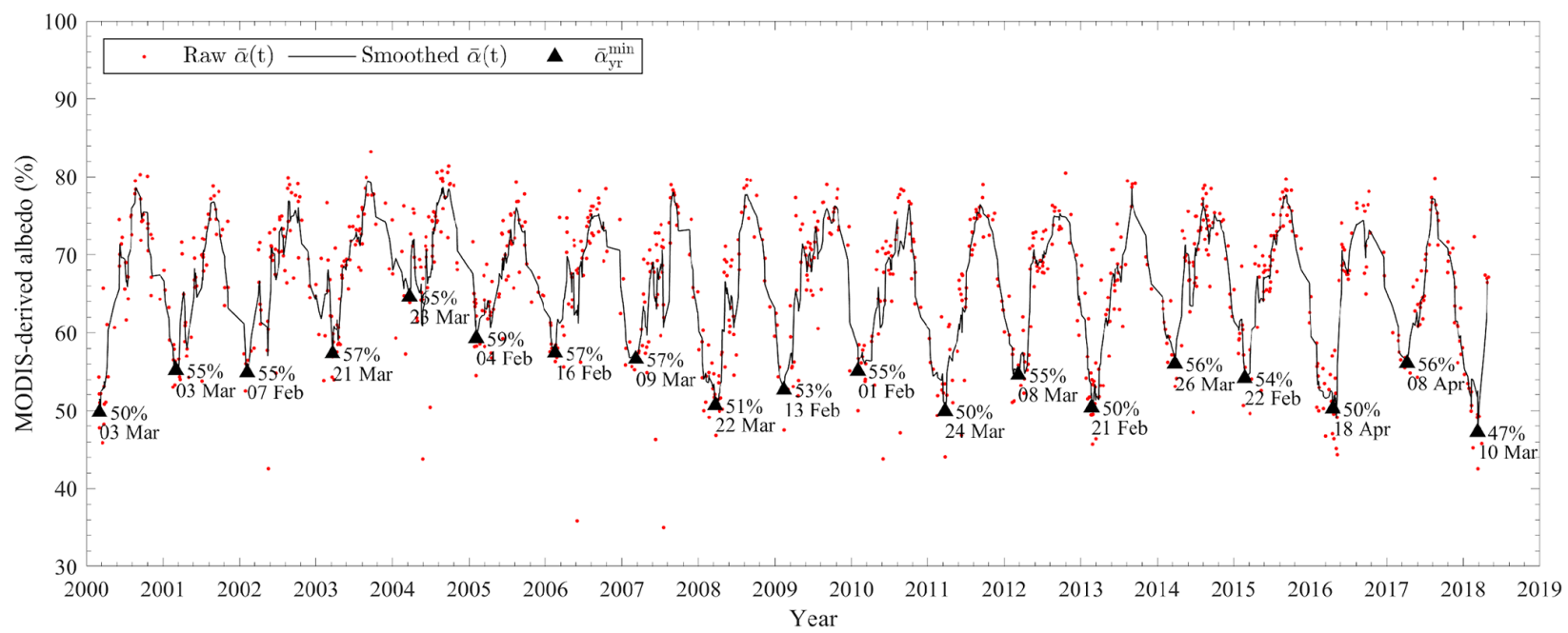

Figure 8. Near-daily MODIS-derived glacier-wide surface albedo $\bar{\alpha}(t)$ on Lambert Glacier between February 2000 and April 2018, with the three-period rolling average and annual minimum glacier-wide albedo $\bar{\alpha}_{\mathrm{yr}}^{\min }$ indicated in black.
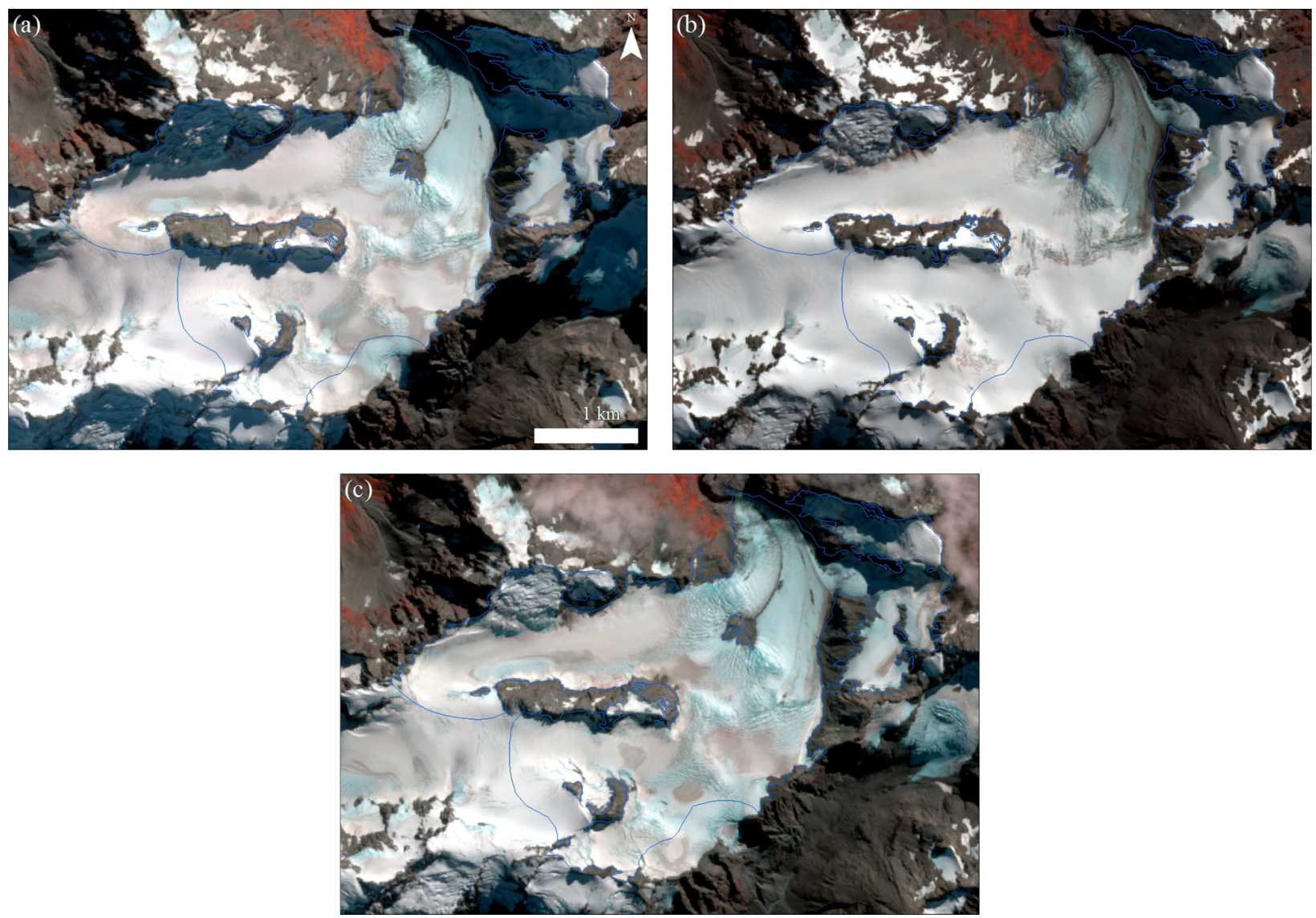

Figure 9. Maximum elevation of the seasonal snowline (approximating the point of maximum ablation) on Lambert Glacier (outlined in blue) observable in cloud-free Sentinel-2A and Sentinel-2B images from (a) 30 April 2016, (b) 29 March 2017 and (c) 29 March 2018. 


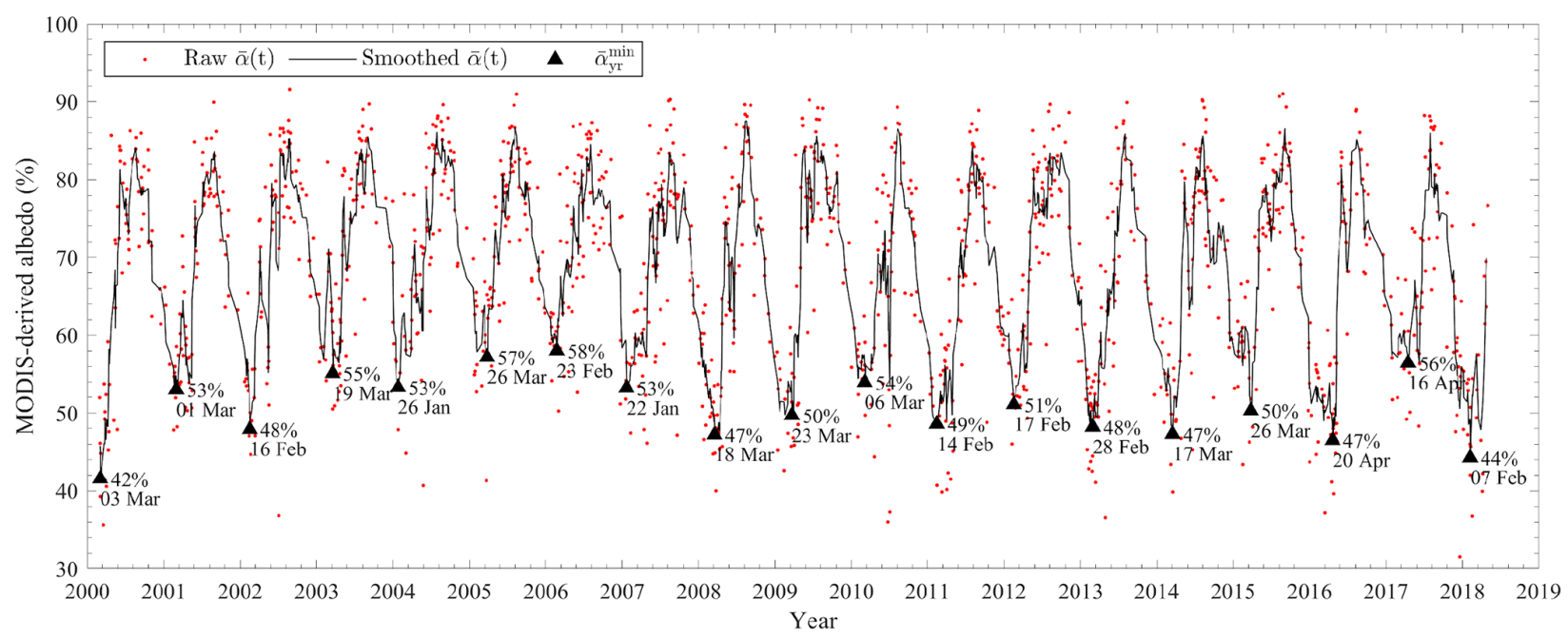

Figure 10. MODIS-derived glacier-wide surface albedo $\bar{\alpha}(t)$ on Vertebrae Col 25 between February 2000 and April 2018 , with the threeperiod rolling average and annual minimum glacier-wide albedo $\bar{\alpha}_{\mathrm{yr}}^{\min }$ indicated in black.

\subsection{Links between $\bar{\alpha}_{\mathbf{y r}}^{\min }$ and EOSS}

Previous applications of the albedo method to New Zealand glaciers have developed strong relationships $\left(R^{2}=0.89\right.$ and $R^{2}=0.87$; see Sirguey et al., 2016, and Rabatel et al., 2017) between the MODIS-derived $\bar{\alpha}_{\mathrm{yr}}^{\min }$ and EOSS SLA $i$. Across the GoEA, SLA records only exist for both Vertebrae Col glaciers. However, with a $0.7 \mathrm{~km}^{2}$ surface area, Vertebrae Col 25 is substantially smaller than the $2 \mathrm{~km}^{2}$ recommended to develop a reliable glacier-wide albedo average with enough MODIS pixels (Sirguey et al., 2016). Although the albedo signal for Vertebrae Col 25 is obtained from only eleven $250 \mathrm{~m}$ resolution pixels, the time series appears to reflect the typical seasonal cycle of albedo, albeit with a larger range in the maximum and minimum albedos than those observed from Lambert Glacier (Fig. 10).

Between 2000 and 2017, the MODIS record of $\bar{\alpha}_{\mathrm{yr}}^{\min }$ for Vertebrae Col 25 explains nearly half of the variability observed in the EOSS SLA $i$ (Fig. $11 ; R^{2}=0.43, p=0.003$ ). Alternatively, $\bar{\alpha}_{\mathrm{yr}}^{\min }$ of Angel Glacier exhibits the strongest relationship with EOSS observations at Vertebrae $\mathrm{Col} 25$, accounting for $69 \%$ of its variance $(p<0.001)$. Other glaciers in the GoEA, namely Lambert, East Lambert and Eve, each capture half or more of this variance as well $(52 \%, 50 \%$ and $55 \%$, respectively). Overall, it appears that the relationship between EOSS observations at Vertebrae Col 25 and $\bar{\alpha}_{\mathrm{yr}}^{\min }$ of each glacier is related to topographic shading $\left(R^{2}=0.48\right.$, $p=0.012)$, slope $\left(R^{2}=0.42, p=0.022\right)$ and the northsouth component of glacier aspect $\left(R^{2}=0.34, p=0.045\right)$. In contrast, glacier size $\left(R^{2}=0.03, p=0.609\right)$ and elevation $\left(R^{2}=0.20, p=0.142\right)$ exhibit no significant role in determining this relationship. From the clustering analysis of the 12 glaciers in the GoEA, it is evident that changes in $\bar{\alpha}_{\mathrm{yr}}^{\min }$ over the unconfined glaciers in Cluster 1 are consistent

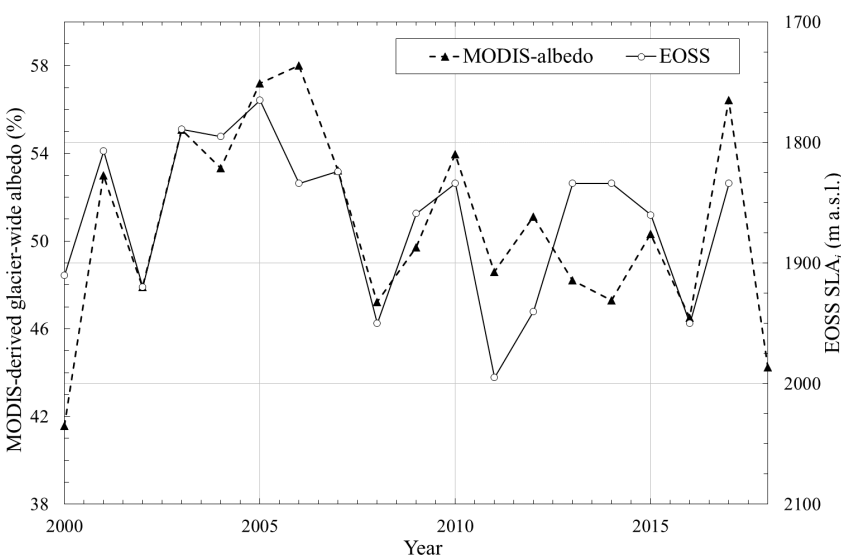

Figure 11. Comparison of MODIS-derived $\bar{\alpha}_{\mathrm{yr}}^{\min }$ and EOSS SLA $i$ on Vertebrae Col 25 between 2000 and $2018\left(R^{2}=0.43\right)$.

with EOSS observations (mean $R^{2}=0.51$ ). More confined west-facing glaciers of Cluster 3 exhibit a weaker relationship (mean $R^{2}=0.36$ ). Finally, $\bar{\alpha}_{\mathrm{yr}}^{\min }$ of the two most confined south-facing glaciers in Cluster 2 do not have a strong relationship to the EOSS record (mean $R^{2}=0.19$ ).

\subsection{The contribution of Aqua MODIS}

\subsubsection{MODIS albedo}

Figure 12a illustrates the agreement between the MODImLab $250 \mathrm{~m}$ WS albedo retrieved from Terra and Aqua MODIS images across 4d (3 March 2009, 9 March 2010, 8 March 2012, 10 March 2013). To account for the role of shadows during the albedo retrieval process, each pixel within the GoEA was assigned to one of four "shading classes", depending on the presence of shade in each im- 
age. Pixels in Class 1 were unshaded in both images; Class 2 and Class 3 pixels were only shaded in the Aqua or Terra image, respectively, and Class 4 pixels were shaded in both images. Of the total 2196 matching pixels from these image pairs, $83.5 \%$ belonged to Class 1 . The linear regression for these 1834 pixels is significant $(p<0.01)$ and strong $\left(R^{2}=0.58\right)$, although slightly askew to a linear $1: 1$ relationship (Fig. 12a). Individually, each of the $4 \mathrm{~d}$ displays a similar trend and distribution, with $R^{2}$ values ranging between 0.51 and 0.71 and gradients between 0.75 and 0.85 .

Figure $12 \mathrm{a}$ also shows an increase in the variability in albedo between the sensors at higher values. Overall, this agreement is consistent with the expected $10 \%$ accuracy of the albedo retrieval method (Dumont et al., 2011, 2012; Sirguey et al., 2016). The increased variability coincides with the highest density of points, where $83 \%$ of pixel albedo values fall between 0.4 and 0.8 . Due to the uneven distribution of albedo across the spectrum, a second linear regression was run on a stratified random sample of 150 Class 1 pixels (Fig. 12b). The linear regression of these resampled data shows a much-improved fit $\left(R^{2}=0.88, p<0.001\right)$ that closely approximates the $1: 1$ relationship and demonstrates that the degraded Band 6 of MODIS ${ }^{\mathrm{A}}$ does not compromise MODImLab albedo retrieval. The slightly lower albedo found in Aqua images compared to Terra may also be explained by the timing, as snow and ice surfaces would undergo transformation compatible with a decrease in albedo from morning to afternoon.

To characterise the variability between the sensors in more detail, we present the spatial distribution of averaged residuals between maps of glacier surface albedo from MODIS ${ }^{\mathrm{T}}$ and MODIS ${ }^{\mathrm{A}}$ across the GoEA (Fig. 13). Although Fig. 13 confirms the good agreement between the sensors over large parts of the GoEA, it shows large departures around the fringes and near rock outcrops $(+0.23$ and -0.38$)$, often close to steep, complex terrain and involving mixed pixels. In particular, two large steep-sided rock outcrops in the south of Lambert Glacier and the west icefall of Angel Glacier descending from Mt Farrar correspond to MODIS ${ }^{\mathrm{A}}$ albedo being substantially larger than MODIS ${ }^{\mathrm{T}}$. Close inspection of imagery before and after correction, as well as of shadow maps, reveals the larger extent of cast shadows produced by outcrops in the afternoon and affecting MODIS ${ }^{\mathrm{A}}$ imagery. Issues of overcorrecting spectral reflectance in cast shadows is known to challenge MODImLab (Davaze et al., 2018) and appears again to cause overestimates of MODIS ${ }^{\mathrm{A}}$ albedo. Figure 12 also demonstrates this effect with overestimation of albedo by MODIS ${ }^{\mathrm{A}}$ relative to $\mathrm{MODIS}^{\mathrm{T}}$ for Class 2 pixels (MODIS ${ }^{\mathrm{A}}$ pixels in the shade) and conversely for Class 3 pixels (MODIS ${ }^{T}$ pixels in the shade).

MODIS $^{\mathrm{A}}$ involves a delay in image capture from 10:30 LT to 13:30 LT. Towards the winter solstice, this decreases the proportion of shaded pixels in the steep terrain of the Southern Alps. The change in the solar zenith angle caused by the delayed timing of the image capture means pixels on south- and southwest-facing slopes have a higher chance of receiving incident radiation. This effect was seen across the GoEA, where a much lower proportion of the total pixels in the GoEA was shaded in MODIS ${ }^{\mathrm{A}}$ images captured near the winter solstice, compared to MODIS $^{\mathrm{T}}(34.5 \%$ and $49.8 \%$, respectively). However, in summer and towards April, steep rock outcrops cast large shadows in the afternoon that challenge albedo retrieval with MODIS ${ }^{\mathrm{A}}$. By May, low sun zenith angles cast longer shadows that are not accurately modelled due to the resolution and accuracy of the DEM. Unpredicted shadows yield severe underestimations of surface albedo, in particular affecting confined glaciers of Cluster 3. Although MODIS ${ }^{\mathrm{A}}$ images could help capture a better albedo signal in such cases, Fig. 5a demonstrates that, over the period of this study, imagery from MODIS ${ }^{\mathrm{T}}$ remained suitable for capturing $\bar{\alpha}_{\mathrm{yr}}^{\min }$ before this issue becomes problematic by May. Nevertheless, despite the computational burden, the systematic processing of MODIS ${ }^{\mathrm{A}}$ imagery may gain merit as the timing of $\bar{\alpha}_{\mathrm{yr}}^{\mathrm{min}}$ appears to be more often delayed to late summer or early autumn (Fig. 5).

Finally, Lyapustin et al. (2014) documented calibration issues with MODIS Collection 5 (C5) data and concluded that major calibration trends were removed in C6. The stability of the C6 calibration was confirmed by Sayer et al. (2015). In the context of retrieving time series of snow and ice albedo with MODIS, Casey et al. (2017) stressed how C5 data could compromise the detection and interpretation of trends and concluded that C6 is preferable. In the case of MODIS Terra, albedo time series derived from C6 data by MODImLab shown in Figs. 8 and 10 reveal no visible trend in winter albedo. If a trend in winter snow albedo existed, it seems unlikely that it would be matched and concealed by a calibration issue of exactly the opposite magnitude. Our results therefore support the alternative hypothesis that there is neither a detectable trend in winter albedo nor a calibration issue over the length of the record produced by this study. This is further supported by the cross-platform agreement shown in Fig. 12.

\subsubsection{MODIS cloud cover}

While MODIS ${ }^{\mathrm{A}}$ potentially provides a means to capture more shadow-free pixels across the GoEA, its use is inhibited by the daily development of cloud cover over the Southern Alps. Figure 14 shows MODIS ${ }^{\mathrm{A}}$ images display a consistently higher proportion of cloudy pixels over the GoEA than MODIS $^{\mathrm{T}}$ images over the course of a year. While this trend is consistent throughout the year, it is pronounced through the summer ablation period, at the critical time when the $\bar{\alpha}_{\mathrm{yr}}^{\min }$ is likely to be observed. A likely driver of this pattern is daytime heating of the atmosphere through the warmer summer months, resulting in convection and aiding cloud development over the course of the day. Ultimately, while MODIS ${ }^{\mathrm{A}}$ shows some promise in its ability to supplement the MODIS ${ }^{\mathrm{T}}$ dataset as discussed above, the high variability in albedo 

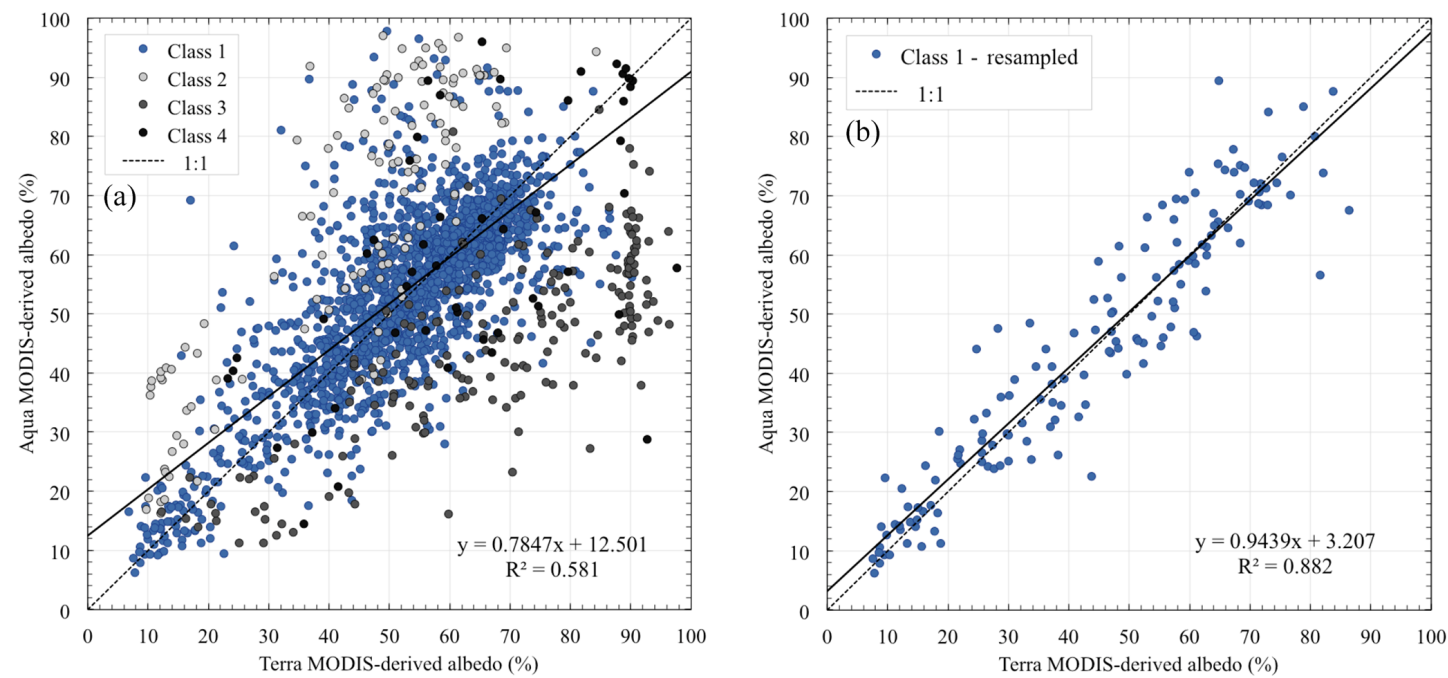

Figure 12. Pixel-by-pixel comparison of MODIS-derived glacier surface albedo across the GoEA, from four pairs of cloud-free Terra and Aqua MODIS images (4 March 2009, 10 March 2010, 9 March 2012, 11 March 2013). Linear regression analysis was performed on (a) all Class 1 pixels $\left(R^{2}=0.58, p<0.001\right)$ and (b) a stratified random sample of 150 Class 1 pixels $\left(R^{2}=0.88, p<0.001\right)$. The dotted line represents the ideal $1: 1$ relationship.

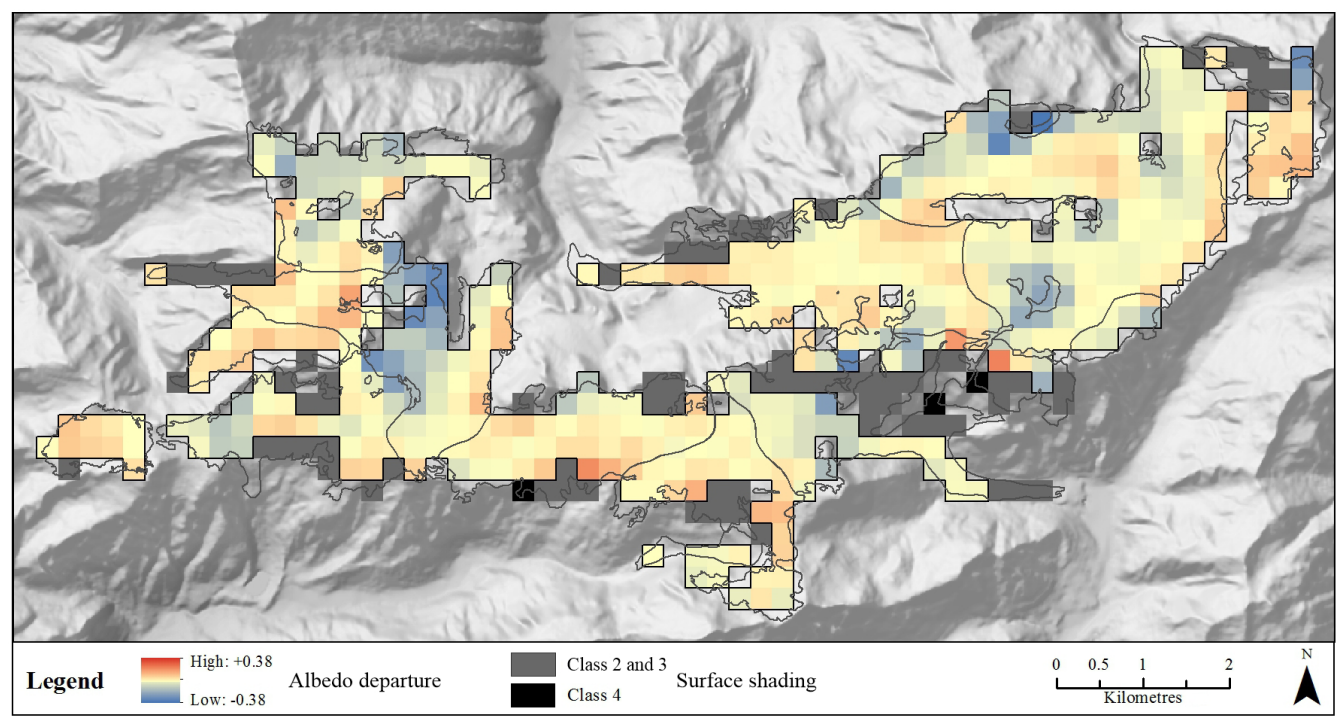

Figure 13. Average departure of MODIS-derived glacier surface albedo for Class 1 pixels between Terra and Aqua images from 4 March 2009, 10 March 2010, 9 March 2012 and 11 March 2013. A positive departure (red pixels) indicates a higher value of albedo in the Terra image. Pixels with shadows have been displayed in grey and black.

from mixed pixels and the daily increase in cloud cover mean that its application is limited in New Zealand.

Interestingly, the cloud cover results from both MODIS ${ }^{\mathrm{A}}$ and MODIS ${ }^{\mathrm{T}}$ images are still of use, as the spatial characterisation of cloud cover over the Southern Alps is very limited (Wardle, 1986). Current research is largely limited to pointbased cloud data from automatic weather stations (e.g. Conway et al., 2015). Cloud cover patterns and dynamics are important for glaciers, as clouds play a key role in influencing incident solar radiation at the glacier surface (Conway and Cullen, 2016). Figure 15 displays the non-uniform distribution of monthly average cloud cover across the processed area. Over the period of study, the frequency of clouds in pixels west of the Main Divide is as high as $90 \%$ during summer months and reaches a minimum of $35 \%$ in some areas during winter, reflecting Fig. 14. During summer, cloud spill-over is limited to within a few kilometres east of the Main Divide, contrasting relatively uniform conditions through winter. It is also possible to identify the presence of "cloud hotspots" that persist through the 19-year record. 


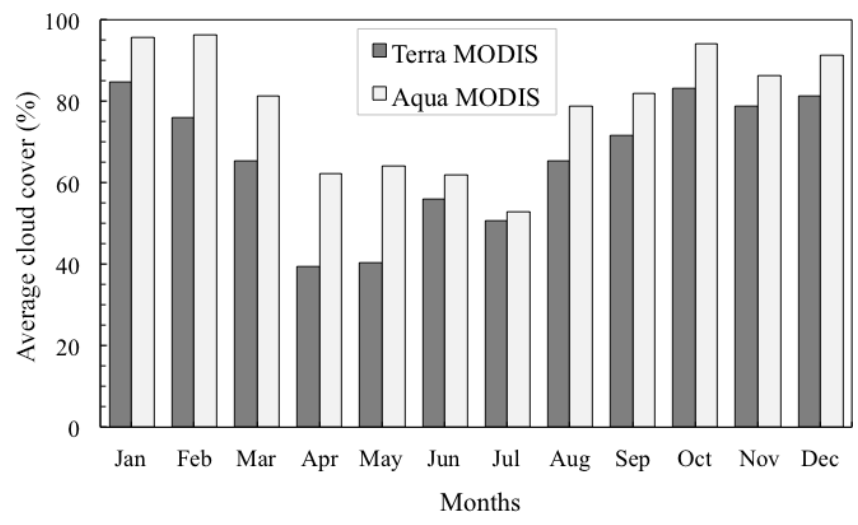

Figure 14. Proportion of pixels over the GoEA obscured by cloud in Terra (10:30 LT) and Aqua (13:30 LT) MODIS images. Monthly averages calculated from 1 January 2012 to 31 December 2012.

\section{Discussion}

\subsection{Comparison to the EOSS survey}

The EOSS survey provides a well-documented and invaluable record of the changes to glaciers in the Southern Alps over the past 40 years. The data collected by the survey bridges the gap in glaciological mass balance records between the termination of the Ivory Glacier programme in 1975 and commencement of the Brewster Glacier programme in 2004. In addition, the correlation between the snowline record and recently developed monitoring methods has allowed past mass balance trends to be reconstructed (e.g. Sirguey et al., 2016). At a larger scale, the use of EOSS $_{\text {Alps }}$ has allowed the annual variability in glacier mass balance in the Southern Alps to be broadly characterised (Chinn et al., 2012; Willsman et al., 2018).

Published relationships developed between the MODISderived $\bar{\alpha}_{\mathrm{yr}}^{\min }$ and the EOSS SLA $i$ departures on Brewster Glacier and Park Pass Glacier were found to be strong (Sirguey et al., 2016; Rabatel et al., 2017). Despite the large differences between the albedo and snowline methodologies, both aim to remotely capture the point of maximum ablation at the glacier surface and use it as a proxy for mass balance. $\mathrm{SLA}_{i}$ - used as an estimate of the ELA - provides an effective measure of glacier mass balance (Rabatel et al., 2005) and should therefore be closely related to $\bar{\alpha}_{\mathrm{yr}}^{\min }$ (Dumont et al., 2012).

However, measuring $\mathrm{SLA}_{i}$ remains difficult, in particular due to uncertainties associated with the method used to identify snowlines from oblique photos. Complex topography, avalanching, fresh snow and cloud cover all present additional challenges for deriving consistent results of $\mathrm{SLA}_{i}$. To compound these challenges, limited resources mean that the EOSS survey is required to assume that SLA $_{i}$ occurs annually in early March, which involves careful timing of the observation flights (Willsman et al., 2018). In most cases,
$\mathrm{SLA}_{i}$ is estimated manually based on the overall appearance of the glacier and snow patches compared to previous years. When $\mathrm{SLA}_{i}$ is digitised, photographs are compared to historical topographic maps or orthorectified images. Furthermore, the methodology often involves an interpretation and assessment of the appearance of an individual glacier in relation to other glaciers in the programme, observed during the same surveys or from different surveys.

Despite the coarse resolution of the MODIS sensor, it has been demonstrated in this study that the albedo method is capable of retrieving robust time series of $\bar{\alpha}_{\mathrm{yr}}^{\min }$ that show strong to moderate relationships to EOSS signals (glaciers of clusters 1 and 3, respectively). There are some clear advantages in using the albedo method over an EOSS approach, which include the approach being repeatable and not being temporally constrained. While the EOSS programme yields an archive of invaluable images, a number of photos are impacted by transient snow that impact the quality of the $\mathrm{SLA}_{i}$ estimates. The timing of the surveys also mean that some $\mathrm{SLA}_{i}$ estimates might not fully capture late-summer melt (Sirguey et al., 2016). Monitoring albedo until the onset of the accumulation season (winter) allows sustained lateseason ablation to be recorded. The large variability in timing of $\bar{\alpha}_{\mathrm{yr}}^{\min }$, as well as the apparent trend towards a delayed occurrence for most glaciers in the GoEA (Figs. 5 and 6), demonstrates the benefit of systematically monitoring glacier surface albedo. Thus, the albedo method provides new insights about glaciers in the Southern Alps that are not captured by the EOSS programme.

The EOSS programme reports considerably high intracorrelations across the 50 index glaciers that sample the Southern Alps, with pairwise $R^{2}$ ranging from 0.22 to 0.96 and averaging 0.69. Overall, our systematic application of the albedo method on the limited geographical extent of the GoEA reveals a degree of variability in glacier response that challenges the highly consistent behaviour suggested by the EOSS programme across the Southern Alps. Strong and significant intra-correlations in $\bar{\alpha}_{\mathrm{yr}}^{\min }$ across glaciers of the GoEA exist but do not dominate, with pairwise $R^{2}$ ranging from 0.12 to 0.88 and averaging only 0.52 . Similarly, the correlation between the average GoEA albedo signal and EOSS $_{\text {Alps }}$ is only $R^{2}=0.55$ (see Fig. 7), while the average correlation between $\mathrm{SLA}_{i}$ and $\mathrm{EOSS}_{\mathrm{Alps}}$ is reported at 0.81 . These contrasting results suggest the EOSS approach may have led to spatial and temporal autocorrelation of the SLA records, which in turn build very strong correlations across SLA records of EOSS index glaciers and with EOSS $\mathrm{Alps}_{\text {. The }}$ outcome of this is that it may have dampened or concealed the variability in the mass balance response of glaciers in the Southern Alps. 


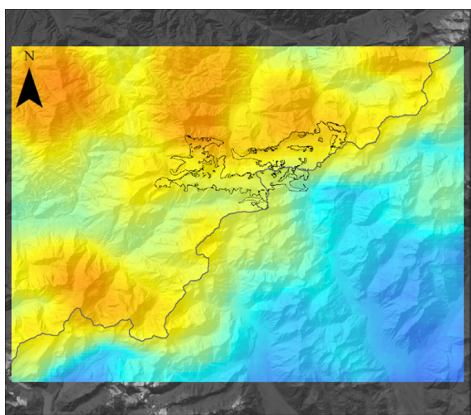

January

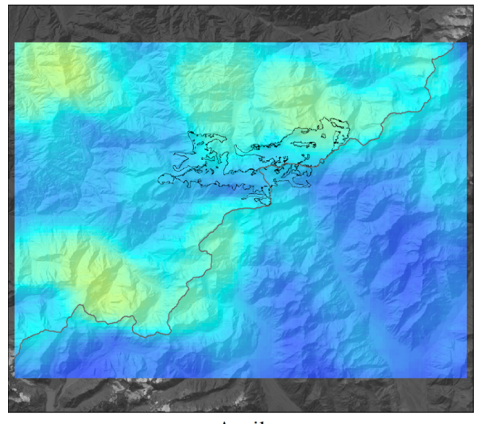

April

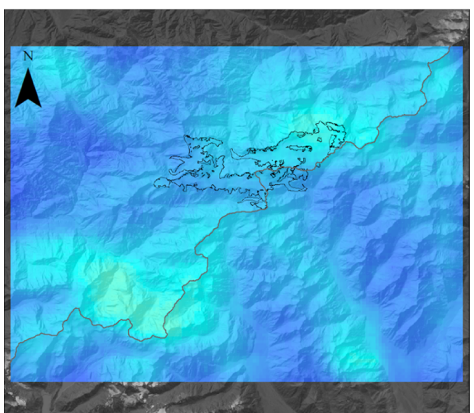

July

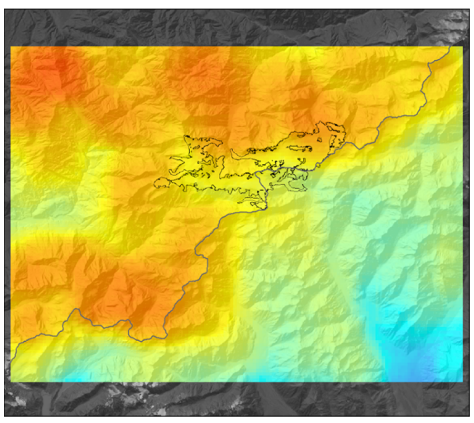

October

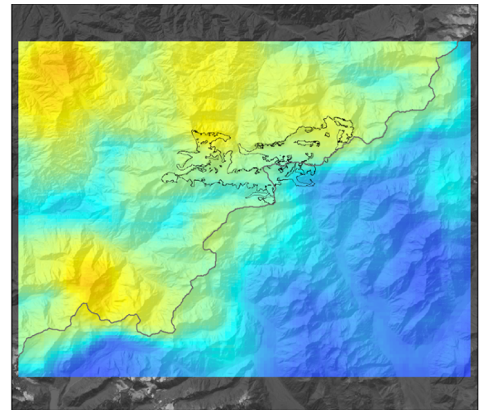

February

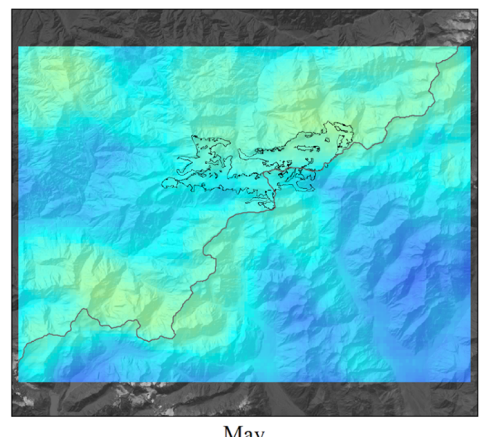

May

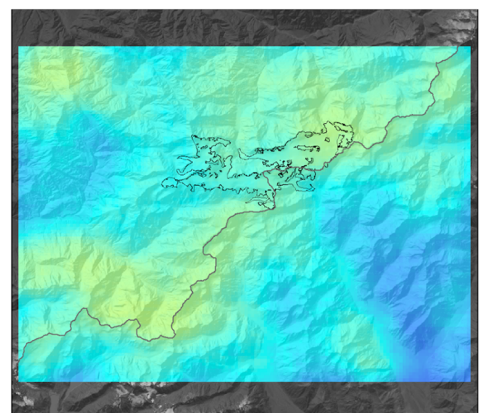

August

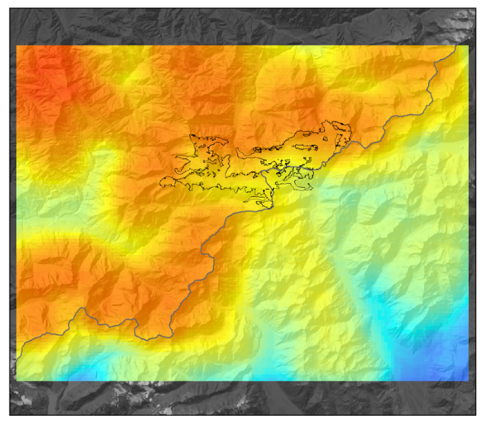

November

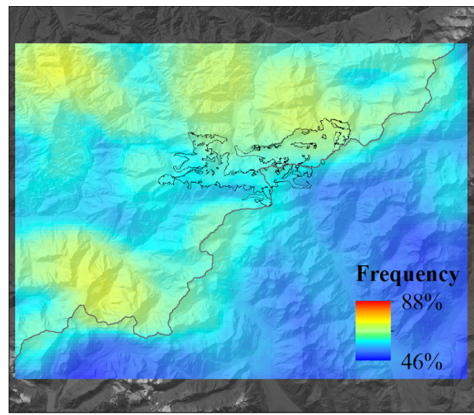

March
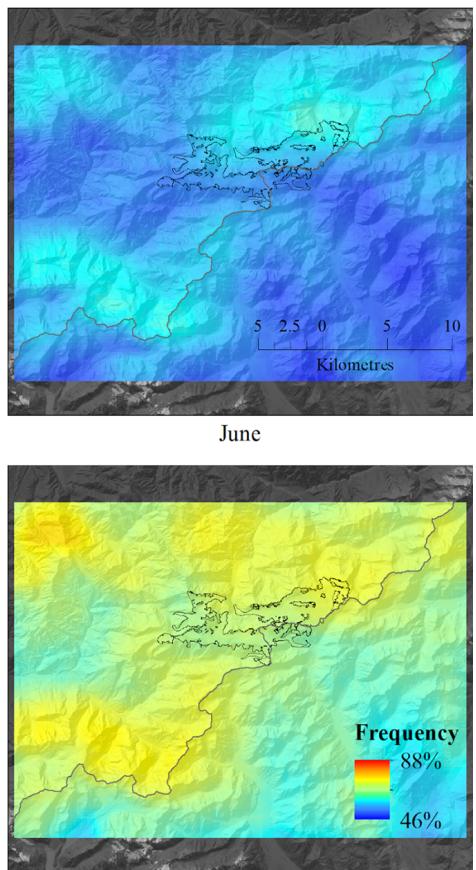

September

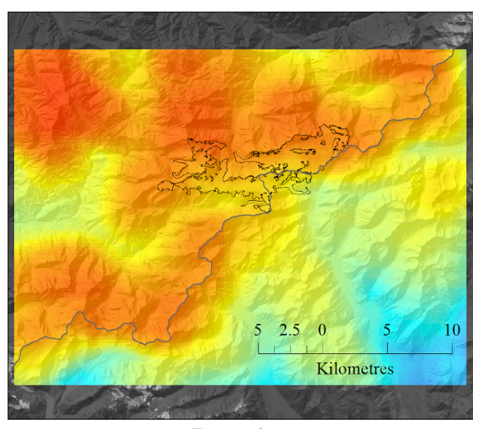

December

Figure 15. Frequency of monthly cloud cover per pixel in Terra MODIS images over the Southern Alps from 2000 to 2017 (frequent cloud cover is displayed in red). The Main Divide of the Southern Alps is shown running southwest to northeast, with the position of the GoEA marked in black.

\subsection{Implications of variability in albedo on mass balance}

Given the scarcity of surface mass balance measurements in the Southern Alps, as well as the spatial and temporal limitations of obtaining imagery from observational flights, satellite remote sensing provides a powerful tool to increase the number of glaciers being currently monitored in New Zealand. To relate the observed variability in albedo to changes in annual mass balance, the relationship between the 
magnitude and timing of $\bar{\alpha}_{\mathrm{yr}}^{\min }$ in each of the three glacier clusters identified on the GoEA (Table 2) needs to be further examined. There is evidence that the occurrence of $\bar{\alpha}_{\mathrm{yr}}^{\min }$ has been delayed in time (later in the year) on all glaciers other than those located on steep, south-facing slopes (Cluster 2; Fig. 5d). Intuitively, a delay in the timing of $\bar{\alpha}_{\mathrm{yr}}^{\min }$ on 10 of the 12 glaciers (clusters 1 and 3 ) might be expected to result in a more negative summer mass balance by virtue of the ablation season being extended. However, there is no visible trend in the magnitude of $\bar{\alpha}_{\mathrm{yr}}^{\min }$ in any of the clusters during the observation period (2000-2018). Also, there is only a weak relationship between a delay in timing and the magnitude of $\bar{\alpha}_{\mathrm{yr}}^{\min }$ (Fig. 5c), suggesting that glacier-wide albedo is not necessarily lower if it is delayed. We interpret this dichotomy as evidence that the atmospheric controls on mass balance are complex and that the magnitude of ablation is in part sensitive to discrete weather events (Cullen et al., 2019), which either bring snowfall (increase albedo) or enhance ablation (decrease albedo) in summer. There is also compelling evidence that clouds play an important role in modulating the energy available for ablation over glaciers in the Southern Alps (Conway and Cullen, 2016) and are likely to influence both the timing and magnitude of $\bar{\alpha}_{\mathrm{yr}}^{\min }$ in the GoEA, thus confounding the relationship. In particular, clouds are very common to the west of the Main Divide in the GoEA region during summer (Fig. 15), and their spatial and temporal variability elsewhere may be an underlying factor in controlling the observed variability in $\bar{\alpha}_{\mathrm{yr}}^{\min }$. We believe there is a risk that some of this complexity is being missed using the singlesnapshot approach of the traditional EOSS programme. Arguably, the albedo method provides more certainty in the atmospheric controls on mass balance, as it provides a platform of continuous observations of albedo and cloud cover over a large number of glaciers throughout the ablation season.

Despite the observed complexity between the timing and magnitude of $\bar{\alpha}_{\mathrm{yr}}^{\min }$ over the observation period, there is evidence of a shift towards more negative annual departures of the mean $\bar{\alpha}_{\mathrm{yr}}^{\min }$ since 2008 (Fig. 7), which is consistent with the EOSS record, implying cumulative losses in mass balance for the glaciers of the GoEA. This mass loss is consistent with glaciological observations of mass balance from Brewster Glacier (Cullen et al., 2017) and the modelling of glacier response to changes in climate in the Southern Alps (Mackintosh et al., 2017; Salinger et al., 2019a, b). This shift towards mass loss appears to be widespread, with the 2018 summer heatwave reportedly the most damaging for glaciers in the Southern Alps over the last half century (Salinger et al., 2019a). We anticipate that the GoEA are particularly vulnerable to a warming climate, as the average elevation of the ice fields is close to the regional snowline, which is estimated to be $1950 \mathrm{~m}$ a.s.l. (Chinn, 2001). Cullen and Conway (2015) showed that the majority of precipitation at the altitude of Brewster Glacier falls at an air temperature that is very close to the threshold between snow and rain. Thus, small increases in air temperature controlled by warming is likely to impact the amount of precipitation falling as snow on the GoEA, which in turn will impact surface albedo and mass balance, potentially driving a rapid decline under a sustained warming trend. While the observations we have obtained using the albedo method suggest that most glaciers are vulnerable, the contrasting response of glaciers contained on steep, southfacing slopes (Cluster 2) indicates they are likely to survive this demise longer.

Lastly, the positioning of the GoEA across the Main Divide of the Southern Alps is particularly important from a management perspective. Because the ice fields straddle the Main Divide, they contribute meltwater to the catchments of the Rangitata River on the east coast and the Wanganui and Whataroa rivers to the west. Given the important role of snow and ice in New Zealand's water resources, changes in the volume of these ice fields have the potential to impact the hydrology of these rivers in the future.

\subsection{Limitations and developments of the albedo method}

The results presented in this study rely on the inherent accuracy of MODImLab. The specific error associated with the MODImLab retrieval over the GoEA is uncertain due to the lack of in situ data. However, Dumont et al. (2012) quantified the relative error between field measurements and the MODImLab $250 \mathrm{~m}$ broadband albedo to be approximately $\pm 10 \%$ (RMSE $=0.052$ ), confirmed by Sirguey et al. (2016). This value is an average estimate, with error recognised to be up to twice as high around the mixed-pixel margins of glaciers compared to the clear snow and ice pixels near the centre (Dumont et al., 2012). As a result, it is expected the uncertainty will be variable between glaciers, where estimates of $\bar{\alpha}(t)$ on large glaciers (i.e. Lambert Glacier) may be more reliable than those on small glaciers with high edge effects (i.e. East Lambert Icefall; Brun et al., 2015).

Supporting Rabatel et al. (2017) and Davaze et al. (2018), we find that the error in the albedo retrieval caused by surface shading does not affect the identification of the summer $\bar{\alpha}_{\mathrm{yr}}^{\min }$. On glaciers where shading is most prominent (steeply sloping, south-facing, topographically incised), we show the $\bar{\alpha}_{\mathrm{yr}}^{\min }$ is typically reached much earlier than early April (when the shading-induced decrease in $\bar{\alpha}(t)$ begins). This means that while New Zealand has a large number of glaciers that exhibit similar hypsometry to those glaciers in Cluster 2, in most cases, the albedo retrieval will still yield reliable values of $\bar{\alpha}_{\mathrm{yr}}^{\min }$.

The masking technique proposed in this study should simplify the process of objectively converting glacier outlines to glacier masks. As we show in Sects. 3.2 and 4.1, the new approach to masking glacier boundaries over the GoEA yields values of $\bar{\alpha}(t)$ over the ablation period within $3 \%$ of the more subjective method employed by previous studies. The success of this technique may support the rapid application of the albedo method to new glaciers using existing outlines, re- 
gardless of whether they are made up of mixed-pixels and/or debris-cover. In addition, the snow-covered-area filter may help to reduce some of the problems of using a static glacier mask (e.g. the glacier extent changing substantially over the observation period).

Finally, the use of MODIS imagery to apply the albedo method remains applicable only for glaciers that are large enough to allow albedo to be retrieved and averaged over a number of pixels. Davaze et al. (2018) show that $\bar{\alpha}_{\mathrm{yr}}^{\min }$ can be successfully retrieved on glaciers covering as little as $0.5 \mathrm{~km}^{2}$ with good correlation to annual mass balance. This is consistent with the agreement we obtained between $\bar{\alpha}_{\mathrm{yr}}^{\min }$ and EOSS on Vertebrae Col $25\left(0.7 \mathrm{~km}^{2}\right.$ or 11 pixels), although it is believed to stretch the reliance on MODIS for the albedo method. The temporal resolution achievable by combining multispectral imaging from higher-resolution sensors such as Sentinel-2 and Landsat 8 OLI justifies the development of snow and ice albedo products to resolve $\bar{\alpha}_{\mathrm{yr}}^{\min }$ on smaller glaciers. Such development is desirable to advance the albedo method and support the widespread monitoring of New Zealand glaciers.

\section{Conclusions}

The results from this study represent the next step towards the use of the albedo method for widespread monitoring of glaciers in the Southern Alps. Following the successful application to Brewster Glacier and Park Pass Glacier, we have produced a 19-year long coherent seasonal signal of glacierwide albedo on the previously unstudied gardens of Eden and Allah (GoEA). These results have supported and advanced key aspects of the methodology that will inform future applications in the Southern Alps and beyond. The key findings can be summarised as follows:

1. A new objective glacier masking approach has been developed that compares favourably to a more traditional manual method of identifying suitable pixels to calculate glacier-wide albedo.

2. The annual minimum glacier-wide albedo $\left(\bar{\alpha}_{\mathrm{yr}}^{\min }\right)$ for individual glaciers ranges between 0.42 and 0.70 , and can occur as early as mid-January and as late as the end of April. The timing of $\bar{\alpha}_{\mathrm{yr}}^{\min }$ appears to have shifted to later in the year over the 19-year period on all glaciers other than those located on steep, south-facing slopes. However, there is only a weak relationship between the delay in timing and the magnitude of $\bar{\alpha}_{\mathrm{yr}}^{\mathrm{min}}$, which suggests that glacier-wide albedo is not necessarily lower if it is delayed.

3. The glacier-wide surface albedo anomaly for the 19year period explains $55 \%$ of the variability in the average annual departure of the 50 index glaciers from the EOSS programme $\left(\right.$ EOSS $\left._{\text {Alps }}\right)$. The largest negative de- partures in $\bar{\alpha}_{\mathrm{yr}}^{\min }$ (lower than average albedo) are consistent with high snowlines, with the 2018 departure the most negative on record. This is consistent with Brewster Glacier and was caused by a marine and terrestrial heatwave over New Zealand (Salinger et al., 2019a).

4. The MODIS record of $\bar{\alpha}_{\mathrm{yr}}^{\min }$ for Vertebrae Col $25 \mathrm{ex}-$ plains less than half of the variability observed in the EOSS SLA record $\left(R^{2}=0.43, p=0.003\right)$. However, the relationship is stronger when compared to other GoEA glaciers, with Angel Glacier having the strongest relationship with EOSS observations at Vertebrae Col 25 , accounting for $69 \%$ of its variance $(p<0.001)$. Lambert, East Lambert, and Eve glaciers each capture half or more of the variance $(52 \%, 50 \%$, and $55 \%$, respectively). The relationship between EOSS observations at Vertebrae Col 25 and $\bar{\alpha}_{\mathrm{yr}}^{\min }$ of each glacier is related in order of importance to topographic shading, slope and aspect.

5. The EOSS programme has reported on how strongly each of the 50 index glaciers behaviour is related to the mean of all remaining glaciers (known as EOSS $_{\text {Alps }}$ ), and pairwise regression shows there is high intra-correlation between glaciers. However, the albedo method enables the variability in response of individual glaciers to be explored in more detail, revealing that topographic setting plays a second order control in addition to the regional climate signal (first order control). The albedo method captures enough individual glacier variability on the GoEA to firmly question the validity of the hypothesis that glaciers in the Southern Alps behave as a single climatic unit.

6. For the first time, MODIS imagery acquired by the Aqua platform (MODIS ${ }^{\mathrm{A}}$ ) has been used successfully to increase the temporal resolution of albedo monitoring using the MODImLab algorithm. There is some evidence to suggest it is capable of capturing diurnal variability in albedo as controlled by changes to snow and ice properties during the daytime. Despite cloud being more frequent during the afternoon, especially in summer, there are advantages in using MODIS ${ }^{\mathrm{A}}$ due to higher incident radiation (less shading) on some slopes at certain times of the year.

7. Cloud cover results from MODIS imagery acquired by the Terra $\left(\right.$ MODIS $^{\mathrm{T}}$ ) and Aqua (MODIS ${ }^{\mathrm{A}}$ ) platforms show the spatial and temporal variability in clouds. The frequency of cloud in pixels west of the Main Divide is as high as $90 \%$ during summer months, and reaches a minimum of $35 \%$ in some locations in winter. There is a strong gradient in cloud cover frequency between regions west and east of the Main Divide, and specific areas appear to be consistently cloudier than others. These complex cloud interactions deserve further attention as 
they are likely to play a considerable role in glacier surface energy and mass balance.

The key findings presented in this research have provided a platform to further develop and extend the application of the albedo method to monitor glacier behaviour in the Southern Alps. The next logical step will be to attempt an assessment of all of the main glaciated areas of the Southern Alps together at a high temporal resolution, which will complement observations made by the EOSS programme and expand our understanding of the linkages between glaciers and the climate system. There is some urgency to do this as our observations of the GoEA, as well as those obtained from traditional glaciological observations elsewhere, suggest that glaciers in the Southern Alps are undergoing an unprecedented decline at present.

Code and data availability. MODIS data used in this research are freely available from the Level-1 and Atmosphere Archive and Distribution System (LAADS) web interface (https://modaps.modaps. eosdis.nasa.gov/services/about/products/c6/, last access: 9 October 2020, MODIS, 2020). NZSoSDEM is freely available from the Koordinates geographical data repository (https://koordinates.com/ layer/3748-22-timaru-15m-dem-nzsosdem-v10/, last access: 9 October 2020, University of Otago, 2020). The MODImLab software is available upon request from Pascal Sirguey.

Author contributions. PS and NJC initiated and coordinated the study. NJC and PS obtained funding for the research. AJD and PS processed and analysed the MODIS data. AJD wrote the first draft of the manuscript, while PS and NJC were responsible for the submission and revision of the final research.

Competing interests. The authors declare that they have no conflict of interest.

Acknowledgements. The field component of this research was supported by the Department of Conservation under the concession 52174-RES. Angus J. Dowson was funded by a postgraduate scholarship from the University of Otago, while Nicolas J. Cullen received support from the Alexander von Humboldt Foundation, Germany, to help support the completion of this research. The MODIS Level-1B data were processed by the MODIS Adaptive Processing System (MODAPS) and the Goddard Distributed Active Archive Center (DAAC) and are archived and distributed by the Goddard DAAC. We thank Etienne Berthier for enabling the acquisition of Airbus DS Pléiades imagery within the Pléiades Glaciers Observatory (PGO) initiative of the ISIS-CNES programme. The authors also thank both the referees for their reviews and constructive comments.

Financial support. This research has been supported by the University of Otago (Research Master's scholarship, Otago University Re- search Grant, grant no. 0112-0313, and Otago University Research Grant, grant no. 0118-0319) and the Brian Mason Scientific and Technical Trust.

Review statement. This paper was edited by Valentina Radic and reviewed by two anonymous referees.

\section{References}

Ackerman, S., Strabala, K., Menzel, W., Frey, R., Moeller, C., and Gumley, L.: Discriminating clear sky from clouds with MODIS, J. Geophys. Res., 103, 32141-32157, https://doi.org/10.1029/1998JD200032, 1998.

Anderton, P. W. and Chinn, T. J.: Ivory Glacier, Representative Basin for Glacial Region 1969-71, 1971-72, Technical Report No. 28, Ministry of Works, Wellington, New Zealand, 1973.

Anderton, P. W. and Chinn, T. J.: Ivory Glacier, New Zealand, an I.H.D. representative basin study. J. Glaciol., 20, 67-84, 1978.

Brun, F., Dumont, M., Wagnon, P., Berthier, E., Azam, M. F., Shea, J. M., Sirguey, P., Rabatel, A., and Ramanathan, Al.: Seasonal changes in surface albedo of Himalayan glaciers from MODIS data and links with the annual mass balance, The Cryosphere, 9, 341-355, https://doi.org/10.5194/tc-9-341-2015, 2015.

Casey, K. A., Polashenski, C. M., Chen, J., and Tedesco, M.: Impact of MODIS sensor calibration updates on Greenland Ice Sheet surface reflectance and albedo trends, The Cryosphere, 11, 17811795, https://doi.org/10.5194/tc-11-1781-2017, 2017.

Chinn, T. J. H.: Glacier Inventory of New Zealand, Technical report, Institute of Geological and Nuclear Sciences, Dunedin, New Zealand, 1991.

Chinn, T. J. H.: Distribution of the glacial water resources in New Zealand, J. Hydrol. (NZ), 40, 139-187, 2001.

Chinn, T., Fitzharris, B., Willsman, A., and Salinger, M.: Annual ice volume changes 1976-2008 for the New Zealand Southern Alps, Global Planet. Change, 92-93, 105-118, https://doi.org/10.1016/j.gloplacha.2012.04.002, 2012.

Cogley, J. G., Hock, R., Rasmussen, L. A., Arendt, A. A., Bauder, A., Braithwaite, R. J., Jansson, P., Kaser, G., Möller, M., Nicholson, L., and Zemp, M.: Glossary of Glacier Mass Balance and Related Terms, Technical report, UNESCO-IHP, Paris, France, 2011.

Columbus, J., Sirguey, P., and Tenzer, R.: A free, fully assessed $15 \mathrm{~m}$ DEM for New Zealand, Survey Quarterly, 66, 16-19, 2011.

Conway, J. P. and Cullen, N. J.: Cloud effects on surface energy and mass balance in the ablation area of Brewster Glacier, New Zealand, The Cryosphere, 10, 313-328, https://doi.org/10.5194/tc-10-313-2016, 2016.

Conway, J. P., Cullen, N. J., Spronken-Smith, R. A., and Fitzsimons, S. J.: All-sky radiation over a glacier surface in the Southern Alps of New Zealand: Characterizing cloud effects on incoming shortwave, longwave and net radiation, Int. J. Climatol., 35, 699-713, https://doi.org/10.1002/joc.4014, 2015.

Cullen, N. J. and Conway, J. P.: A 22 month record of surface meteorology and energy balance from the ablation zone of Brewster Glacier, New Zealand, J. Glaciol., 61, 931-946, https://doi.org/10.3189/2015JoG15J004, 2015. 
Cullen, N. J., Anderson, B., Sirguey, P., Stumm, D., Mackintosh, A., Conway, J. P., Horgan, H. J., Dadic, R., Fitzsimons, S. J., and Lorrey, A.: An 11-year record of mass balance of Brewster Glacier, New Zealand, determined using a geostatistical approach, J. Glaciol., 63, 199-217, https://doi.org/10.1017/jog.2016.128, 2017.

Cullen, N. J., Gibson, P. B., Mölg, T., Conway, J. P., Sirguey, P., and Kingston, D. G.: The influence of weather systems in controlling mass balance in the Southern Alps of New Zealand, J. Geophys. Res.-Atmos., 124, 4514-4529, https://doi.org/10.1029/2018JD030052, 2019.

Davaze, L., Rabatel, A., Arnaud, Y., Sirguey, P., Six, D., Letreguilly, A., and Dumont, M.: Monitoring glacier albedo as a proxy to derive summer and annual surface mass balances from optical remote-sensing data, The Cryosphere, 12, 271-286, https://doi.org/10.5194/tc-12-271-2018, 2018.

Dumont, M., Sirguey, P., Arnaud, Y., and Six, D.: Monitoring spatial and temporal variations of surface albedo on Saint Sorlin Glacier (French Alps) using terrestrial photography, The Cryosphere, 5, 759-771, https://doi.org/10.5194/tc-5-759-2011, 2011.

Dumont, M., Gardelle, J., Sirguey, P., Guillot, A., Six, D., Rabatel, A., and Arnaud, Y.: Linking glacier annual mass balance and glacier albedo retrieved from MODIS data, The Cryosphere, 6, 1527-1539, https://doi.org/10.5194/tc-6-1527-2012, 2012.

Fitzharris, B., Lawson,W., and Owens, I.: Research on glaciers and snow in New Zealand, Prog. Phys. Geog., 23, 469-500, https://doi.org/10.1177/030913339902300402, 1999.

Gillett, S. and Cullen, N. J.: Atmospheric controls on summer ablation over Brewster Glacier, New Zealand, Int. J. Climatol., 31, 2033-2048, https://doi.org/10.1002/joc.2216, 2011.

Greuell, W., Kohler, J., Obleitner, F., Glowacki, P., Melvold, K., Bernsen, E., and Oerlemans, J.: Assessment of interannual variations in the surface mass balance of 18 Svalbard glaciers from the Moderate Resolution Imaging Spectroradiometer/Terra albedo product, J. Geophys. Res., 112, D07105, https://doi.org/10.1029/2006JD007245, 2007.

Henderson, R. D. and Thompson, S. M.: Extreme rainfalls in the Southern Alps of New Zealand, J. Hydrol. (NZ), 38, 309-330, 1999.

Hock, R., Rasul, G., Adler, C., Cáceres, B., Gruber, S., Hirabayashi, Y., Jackson, M., Kääb, A., Kang, S., Kutuzov, S., Milner, A., Molau, U., Morin, S., Orlove, B., and Steltzer H.: High Mountain Areas, in: IPCC Special Report on the Ocean and Cryosphere in a Changing Climate, edited by: Pörtner, H., Roberts, D. C., Masson-Delmotte, V., Zhai, P., Tignor, M., Poloczanska, E., Mintenbeck, K., Alegriá, M., Nicolai, M., Okem, A., Petzold, J., Rama, B., and Weyer, N. M., IPCC, in press, 2019.

Klok, E. J. and Oerlemans, J.: Modelled climate sensitivity of the mass balance of Morteratschgletscher and its dependence on albedo parameterization, Int. J. Climatol., 24, 231-245, https://doi.org/10.1002/joc.994, 2004.

Lyapustin, A., Wang, Y., Xiong, X., Meister, G., Platnick, S., Levy, R., Franz, B., Korkin, S., Hilker, T., Tucker, J., Hall, F., Sellers, P., Wu, A., and Angal, A.: Scientific impact of MODIS C5 calibration degradation and C6+ improvements, Atmos. Meas. Tech., 7, 4353-4365, https://doi.org/10.5194/amt-7-4353-2014, 2014.

Macara, G.: Updated datasets for atmosphere and climate domain report, Client report no. 2017054WN prepared for the Ministry for the Environment, National Institute of Water and Atmospheric Research, National Institute of Water and Atmospheric Research Ltd., Wellington, available at: https://www.mfe.govt.nz/sites/default/files/media/ Environmentalreporting/NIWAdatasetsreport.pdf (last access: 9 October 2020), 2017.

Mackintosh, A. N., Anderson, B. M., Lorrey, A. M., Renwick, J. A., Frei, P., and Dean, S. M.: Regional cooling caused recent New Zealand glacier advances in a period of global warming, Nat. Commun., 8, 14202, https://doi.org/10.1038/ncomms14202, 2017.

Masson, T., Dumont, M., Mura, M., Sirguey, P., Gascoin, S., Dedieu, J.-P., and Chanussot, J.: An Assessment of Existing Methodologies to Retrieve Snow Cover Fraction from MODIS Data, Remote Sens., 10, 619, https://doi.org/10.3390/rs10040619, 2018.

Mathieu, R., Chinn, T., and Fitzharris, B.: Detecting the equilibrium-line altitudes of New Zealand glaciers using ASTER satellite images, New Zeal. J. Geol. Geop., 52, 209-222, https://doi.org/10.1080/00288300909509887, 2009.

MODIS Characterization Support Team (MCST)/MODIS Adaptive Processing System (MODAPS)/MODIS Science Data Support Team (SDST): MODIS Collection 6 Products, available at: https://modaps.modaps.eosdis.nasa.gov/services/about/ products/c6/, last access: 9 October 2020.

Oerlemans, J.: Climate sensitivity of Franz Josef Glacier, New Zealand, as revealed by numerical modelling, Arctic Alpine Res., 29, 233-239, https://doi.org/10.2307/1552052, 1997.

Oerlemans, J., Giesen, R. H., and Van Den Broeke, M. R.: Retreating alpine glaciers: Increased melt rates due to accumulation of dust (Vadret da Morteratsch, Switzerland), J. Glaciol., 55, 729736, https://doi.org/10.3189/002214309789470969, 2009.

Olson, M. and Rupper, S.: Impacts of topographic shading on direct solar radiation for valley glaciers in complex topography, The Cryosphere, 13, 29-40, https://doi.org/10.5194/tc-13-29-2019, 2019.

Pfeffer, W. T., Arendt, A. A., Bliss, A., Bolch, T., Cogley, J. G., Gardner, A. S., Hagen, J.-O., Hock, R., Kaser, G., Kienholz, C., Miles, E. S., Moholdt, G., Mölg, N., Paul, F., Radic, V., Rastner, P., Raup, B. H., Rich, J., Sharp, M. J., Andreassen, L. M., Bajracharya, S., Barrand, N. E., Beedle, M. J., Berthier, E., Bhambri, R., Brown, I., Burgess, D. O., Burgess, E. W., Cawkwell, F., Chinn, T., Copland, L., Cullen, N. J., Davies, B., Angelis, H. D., Fountain, A. G., Frey, H., Giffen, B. A., Glasser, N. F., Gurney, S. D., Hagg, W., Hall, D. K., Haritashya, U. K., Hartmann, G., Herreid, S., Howat, I., Jiskoot, H., Khromova, T. E., Klein, A., Kohler, J., König, M., Kriegel, D., Kutuzov, S., Lavrentiev, I., Bris, R. L., Li, X., Manley, W. F., Mayer, C., Menounos, B., Mercer, A., Mool, P., Negrete, A., Nosenko, G., Nuth, C., Osmonov, A., Pettersson, R., Racoviteanu, A., Ranzi, R., Sarıkaya, M. A., Schneider, C., Sigurðsson, O., Sirguey, P., Stokes, C. R., Wheate, R., Wolken, G. J., Wu, L. Z., and Wyatt, F. R.: The Randolph Glacier Inventory: a globally complete inventory of glaciers, J. Glaciol., 60, 537-552, https://doi.org/10.3189/2014JoG13J176, 2014.

Pope, E., Willis, I. C., Pope, A., Miles, E. S., Arnold, N. S., and Rees, W. G.: Contrasting snow and ice albedos derived from MODIS, Landsat ETM+ and airborne data from Langjökull, Iceland, Remote Sens. Environ., 175, 183-195, https://doi.org/10.1016/j.rse.2015.12.051, 2016. 
Purdie, H., Rack, W., Anderson, B., Kerr, T., Chinn, T.J., Owens, I., and Linton, M.: The impact of extreme summer melt on net accumulation of an avalanche fed glacier, as determined by ground-penetrating radar, Geogra. Ann. A, 97, 779-791, https://doi.org/10.1111/geoa.12117, 2015.

Rabatel, A., Dedieu, J.-P., and Vincent, C.: Using remote-sensing data to determine equilibrium-line altitude and mass-balance time series: validation on three French glaciers, J. Glaciol., 51, 539-546, https://doi.org/10.3189/172756505781829106, 2005.

Rabatel, A., Dedieu, J.-P., and Vincent, C.: Spatio-temporal changes in glacier-wide mass balance quantified by optical remote sensing on 30 glaciers in the French Alps for the period 1983-2014, J. Glaciol., 62, 1153-1166, https://doi.org/10.1017/jog.2016.113, 2016.

Rabatel, A., Sirguey, P., Drolon, V., Maisongrande, P., Arnaud, Y., Berthier, E., Davaze, L., Dedieu, J.-P., and Dumont, M.: Annual and Seasonal Glacier-Wide Surface Balance Quantified from Changes in Glacier Surface State: A Review on Existing Methods Using Optical Satellite Imagery, Remote Sens., 9, 507, https://doi.org/10.3390/rs9050507, 2017.

Salinger, J., Renwick, J., Behrens, E., Mullan, B., Diamond, H. J., Sirguey, P., Smith, R., Trought, M. C. T., Alexander, L. V., Cullen, N., Fitzharris, B. B., Hepburn, C., Parker, A., and Sutton, P. J.: The unprecedented coupled ocean-atmosphere summer heatwave in the New Zealand region 2017/18: drivers, mechanisms and impacts, Environ. Res. Lett., 14, 044023, https://doi.org/10.1088/1748-9326/ab012a, 2019a.

Salinger, M. J., Fitzharris, B. B., and Chinn, T.: Atmospheric circulation and ice volume changes for the small and medium glaciers of New Zealand's Southern Alps mountain range 1977/2018, Int. J. Climatol., 39, 4274-4287, https://doi.org/10.1002/joc.6072, $2019 b$.

Sayer, A. M., Hsu, N. C., Bettenhausen, C., Jeong, M.-J., and Meister, G.: Effect of MODIS Terra radiometric calibration improvements on Collection 6 Deep Blue aerosol products: Validation and Terra/Aqua consistency, J. Geophys. Res.-Atmos., 120, 12157-12174, https://doi.org/10.1002/2015jd023878, 2015.

Sirguey, P.: Simple correction of multiple reflection effects in rugged terrain, Int. J. Remote Sens., 30, 1075-1081, https://doi.org/10.1080/01431160802348101, 2009.

Sirguey, P., Mathieu, R., Arnaud, Y., Khan, M. M., and Chanussot, J.: Improving MODIS spatial resolution for snow mapping using wavelet fusion and ARSIS concept, IEEE Geosci. Remote S., 5, 78-82, https://doi.org/10.1109/LGRS.2007.908884, 2008.

Sirguey, P., Mathieu, R., and Arnaud, Y.: Subpixel monitoring of the seasonal snow cover with MODIS at $250 \mathrm{~m}$ spatial resolution in the Southern Alps of New Zealand: methodology and accuracy assessment, Remote Sens. Environ., 113, 160-181, https://doi.org/10.1016/j.rse.2008.09.008, 2009.

Sirguey, P., Still, H., Cullen, N. J., Dumont, M., Arnaud, Y., and Conway, J. P.: Reconstructing the mass balance of Brewster Glacier, New Zealand, using MODIS-derived glacier-wide albedo, The Cryosphere, 10, 2465-2484, https://doi.org/10.5194/tc-10-2465-2016, 2016.
Stamnes, K., Tsay, S.-C., Wiscombe, W., and Jayaweera, K.: Numerically stable algorithm for discrete-ordinate-method radiative transfer in multiple scattering and emitting layered media, Appl. Optics, 27, 2502-2509, https://doi.org/10.1364/AO.27.002502, 1988.

University of Otago - National School of Surveying: NZSoSDEM v1.0 (22 Timaru $15 \mathrm{~m}$ DEM), available at: https://koordinates. com/layer/3748-22-timaru-15m-dem-nzsosdem-v10/, last access: 9 October 2020.

Wardle, P.: Frequency of cloud cover on New Zealand mountains in relation to subalpine vegetation, New Zeal. J. Bot., 24, 553-565, 1986.

Willsman, A. P., Chinn, T. J., and Macara, G.: New Zealand Glacier Monitoring: End of summer snowline survey 2016, NIWA Client Report No: 2017167EI, National Institute of Water and Atmospheric Research Ltd., Wellington, 2017.

Willsman, A. P., Chinn, T. J., and Macara, G.: New Zealand Glacier Monitoring: End of summer snowline survey 2017, NIWA Client Report No: 2018176EI, National Institute of Water and Atmospheric Research Ltd., Wellington, 2018.

Wolfe, R. E., Roy, D. P., and Vermote, E.: MODIS land data storage, gridding, and compositing methodology: Level 2 Grid, IEEE T. Geosci. Remote, 36, 1324-1338, https://doi.org/10.1109/36.701082, 1998.

Zemp, M., Hoelzle, M., and Haeberli, W.: Six decades of glacier mass-balance observations: A review of the worldwide monitoring network, Ann. Glaciol., 50, 101-111, https://doi.org/10.3189/172756409787769591, 2009.

Zemp, M., Frey, H., Gärtner-Roer, I., Nussbaumer, S. U., Hoelzle, M., Paul, F., Haeberli, W., Denzinger, F., Ahlstrøm, A. P., Anderson, B., Bajracharya, S., Baroni, C., Braun, L. N., Cáceres, B. E., Casassa, G., Cobos, G., Dávila, L. R., Delgado Granados, H., Demuth, M. N., Espizua, L., Fischer, A., Fujita, K., Gadek, B., Ghazanfar, A., Hagen, J. O., Holmlund, P., Karimi, N., Li, Z., Pelto, M., Pitte, P., Popovnin, V. V., Portocarrero, C. A., Prinz, R., Sangewar, C. V., Severskiy, I., Sigurðsson, O., Soruco, A., Usubaliev, R., and Vincent, C.: Historically unprecedented global glacier decline in the early 21 st century, J. Glaciol., 61, 745-762, https://doi.org/10.3189/2015jog15j017, 2015.

Zemp, M., Huss, M., Thibert, E., Eckert, N., McNabb, R., Huber, J., Barandun, M., Machguth, H., Nussbaumer, S. U., GärtnerRoer, I., Thomson, L., Paul, F., Maussion, F., Kutuzov, S., and Cogley, J. G.: Global glacier mass changes and their contributions to sea-level rise from 1961 to 2016 , Nature, 568, 382-386, https://doi.org/10.1038/s41586-019-1071-0, 2019.

Zhang, Z., Jiang, L., Liu, L., Sun, Y., and Wang, H.: Annual glacierwide mass balance (2000-2016) of the interior Tibetan plateau reconstructed from MODIS albedo products, Remote Sens., 10, 1031, https://doi.org/10.3390/rs10071031, 2018. 